\title{
European bank loan loss provisioning and efficient technological innovative progress
}

\author{
Richard Simper ${ }^{\mathrm{a} *}$, Aristeidis Dadoukis ${ }^{\mathrm{a}}$, Cormac Bryce ${ }^{\mathrm{b}}$. \\ a Centre for Banking, Risk and Financial Services, Nottingham University Business School, University of \\ Nottingham, NG8 1BB, England. \\ ${ }^{\mathrm{b}}$ Faculty of Actuarial Science and Insurance, City, University of London, Cass Business School, London, EC1Y \\ $8 \mathrm{TZ}$.
}

\begin{abstract}
:
This paper presents an analysis of Loan Loss Provisioning (LLP) behavior of European banks across 26-member states to determine how bad management and Technological Innovative Progress (TIP) has affected bank risk management. Technological improvements in banking have seen advances in both back and front office operations with respect to lending. This is created through increased disembodied technological change capturing improvements in both non-financial and risk management technologies. We find, using a new dynamic LLP model that European banks employed bad management practices in relation to their lending and monitoring practices, leading to higher losses on loans (through increased LLPs). However, the relationship between TIP and LLPs indicates that those banks which increased their technological efficiency with respect to costs had a greater ability to recognize bad loans, and were therefore able to subsequently increase LLPs. That is, improving technology mitigated the impact of bad management practices in European banks.
\end{abstract}

Keywords: Loan loss provision accounting; Bad management; Technological innovative progress; Earnings management; Risk management.

JEL Classifications: C33: G01: G28: G21

Funding: This research did not receive any specific grant from funding agencies in the public, commercial, or not-for-profit sectors. 


\title{
European bank loan loss provisioning and technological innovative progress
}

\begin{abstract}
:
This paper presents an analysis of Loan Loss Provisioning (LLP) behavior of European banks across 26-member states to determine how bad management and Technological Innovative Progress (TIP) has affected bank risk management. Technological improvements in banking have seen advances in both back and front office operations with respect to lending. This is created through increased disembodied technological change capturing improvements in both non-financial and risk management technologies. We find, using a new dynamic LLP model that European banks employed bad management practices in relation to their lending and monitoring practices, leading to higher losses on loans (through increased LLPs). However, the relationship between TIP and LLPs indicates that those banks which increased their technological efficiency with respect to costs had a greater ability to recognize bad loans, and were therefore able to subsequently increase LLPs. That is, improving technology mitigated the impact of bad management practices in European banks.
\end{abstract}

Keywords: Loan loss provision accounting; Bad management; Technological innovative progress; Earnings management; Risk management.

JEL Classifications: C33: G01: G28: G21

Funding: This research did not receive any specific grant from funding agencies in the public, commercial, or not-for-profit sectors. 


\section{Introduction}

This paper aims to present the first contribution introducing and testing whether technological innovative progress (TIP) and the effects of increases in scale effects associated with TIP (TIPSB) has had an effect on Loan Loss Provisioning (LLP) risk strategies. As Berger (2003) discusses, technological innovation can come about through internet banking, electronic payments systems and information exchanges (e.g., the increase in the number of ATMs - in the UK ATMS have increased year-on-year from 54,900 in 2004 to 69,600 in 2017). Furthermore, increases in TIP can have a positive effect on productivity and scale efficiencies as banks are able to reduce financing costs and risk through the increased use of derivatives and off-balance sheet activities such as securitization, something found recently by Badunenko \& Kumbhakar (2017). However, to the best of our knowledge, TIP and TIPSB have not, as yet, become a common determinant in the estimation of dynamic models within the LLP literature. The implication of this is that to date, it has not been tested whether TIP or TIPSB affects the LLP risk behavior of bank management - which we find in this research.

This can be considered an important omission within the current literature concerning the potential relationship between TIP, TIPSB and LLP and needs to be considered. Indeed, as banks have advanced their internal processes associated with IT systems, and better managed their loan portfolios through increased risk management modelling, this gives rise to endogeneity in any empirical specification ${ }^{1}$. TIP and TIPSB is therefore an important determinant of the risk management of LLPs in banks and can follow an erratic process over the economic cycle as inputs change due to inventive and innovative progress. In addition, technological advances can also come from external factors including changes in regulation (see Allen \& Liu 2007), which are then implemented by banks internally, or through deregulation and increases in competition (see Liu, 2010 and Badunenko \& Kumbhakar 2017). For example, the Basel accords which were implemented in our sample period resulted in updates to capital requirements and changed the internal risk management characteristics of banks with respect to LLPs (Basel Committee on Banking Supervision, 2004). This seemingly exogenous effect can be internally compartmentalized into banks LLP risk management business models again leading to endogeneity between TIP and LLP (see, Adrian, 2018).

Furthermore, TIP can be said to be embodied or disembodied and as such, technological change becomes an important characteristic of bank risk management behavior dynamically.

\footnotetext{
${ }^{1}$ An excellent review of changes in risk management processes and regulations in banks and their effect on bank operations can be found in a recent IMF paper, Adrian (2018).
} 
We posit that technological innovations in LLP risk management can be embodied in the design of information technology (IT), new regulations, and risk management processes, that are used in both back-end and front-end applications. Which we consider has had an effect on how loan portfolios are monitored, and subsequently the risk assessments utilized when agreeing to loans. As Fukuyama and Weber (2015) argue "financial institutions should be willing to accept nonperforming loans up to the point where the lost income (including principle) on the marginal performing loan is just offset by the reduced monitoring costs or by the increased interest income on the loan portfolio" (page 46). However, embodied technological change with respect to LLPs is difficult to establish unless the researcher has inside information on the system characteristics of banks' IT risk arrangements and thereby their IT cost procurements for risk systems over time (as discussed by Berger, 2003).

To circumvent non-reporting of individual bank spending on technological improvements we proxy TIP by the use of estimating technological change through a cost function (this first stage has been undertaken by Hunter \& Timme, 1991, Drake \& Simper, 2002 and Berger, 2003). Hence, we consider technologies such as information processing (i.e., improved quality in processing deposit and loan customer information), and financial technologies such as, more advance use of risk management statistical techniques (i.e., more efficient future risk evaluation of the loan portfolio) - thus estimating directly disembodied technological change. This so called disembodied technological change therefore provides us with an initial insight to determine whether there are dynamic characteristics that should be considered when analyzing bank LLP risk management behavior (with which we concur).

Finally, our additional contribution is to estimate a comprehensive model that examines the major LLP hypotheses whilst incorporating bad management, TIP and TIPSB in a dynamic second stage specification. However, we have to accept that these additional descriptors with LLP, could be endogenous, thereby leading to problems of estimation in a standard setting. To overcome these problems we follow the approach of system GMM (Arellano \& Bover, 1995 and Blundell \& Bond, 1998) and we conduct a thorough SGMM with additional post estimation diagnostics not commonly reported in previous LLP empirical literature. Unfortunately, the former problem of finding correct instruments and ensuring that a dynamic LLP model is not over instrumentalized has been misinterpreted in the literature, leading to potentially biased and misleading results, which we aim to address. It should be noted at this point the importance of the Hansen J-statistic and how researchers have misinterpreted the estimate and Roodman's p-value equal to a 0.25 lower bound (Roodman, 2009b). Indeed, Roodman (2009a) warns against the 'liberal' use of conventional significance levels when trying to rule out correlation 
between instruments and the error term. For example, Mamatzakis et al. (2013), Table 11, has all 6 models with a Hansen statistic below 0.163, Table 12 with all 4 models below 0.22 and Table 13 with all 5 models having a Hansen below 0.24; Skala's (2015) Models (7) and (8) present p-values equal to 0.17 and 0.03; whereas, Olszak et al. (2016) Table 3 gives actual values (“*** denotes significant at the $1 \%$ level”) equal to $1343.45 * * *$ (Model 3), 1310.45*** (Model 4) and 284.4*** (Model 8), Table 4, Models 2, 3, 5, 6, 7 and 10 all have 'significant at the $1 \%$ level', in Table 5, all 13 different models have 'significant at the $1 \%$ level' and even in their 'robustness check, Table 9 has 9 of the 12 models all rejecting at the $1 \%$ critical level Hansen statistics. Our final contribution is to present a coherent LLP dynamic specification that can therefore explain these numerous theories in a fully specified model.

The remainder of this paper is organized as follows: Section 2 provides a review of previous literature specific to LLP. Section 3 presents our hypotheses. Section 4 provides a detailed justification of our methodological approach with Section 5 discussing the data. Section 6 presents our empirical results and discusses them in the context of both previous studies, with conclusions developed in Section 7.

\section{Literature survey of traditional LLP behavior}

In an economic downturn the nature of LLPs is an important determinant to be analyzed by regulators. That is, if capital fails to cover the growth of bad loans in a recession there could be a potential feedback into the real economy as banks reduce lending to cover these losses by increasing LLPs. This could ultimately exacerbate a downturn in the business cycle through reduced lending as found in European banks (Bouvatier \& Lepetit, 2008). Furthermore, Glen \& Mondragón-Vélez (2011) argue, 'understanding these dynamics' is of importance for investors and regulators to determine what effect macroeconomic downturns could have on bank loan portfolios (see also Anandarajan, Hasan, \& Lozano-Vivas, 2005) and hence inefficiencies. Indeed, the bad management hypothesis argues that these inefficiencies could be created through poor credit monitoring (use of technology), insufficient control of operating costs, and unstable capital. Given that identified credit losses are absorbed by the specific component of LLPs, managers could have an incentive to increase general LLPs thereby reducing future unidentified risks and their effect on Tier 2 capital. Bad management therefore indicates a negative relationship between efficiency and LLPs and is tested directly in our new model. 
Efficiency could also influence future income streams through cost skimping which implies banks cut costs such as loan monitoring and screening for higher short-term profit efficiency. Thus, when banks boost profit efficiency, loan losses could increase in the future, despite an unchanged current level of documented nonperforming loans (NPLs). Therefore, low efficiency could encourage managers to add more general LLPs for future safety whilst not increasing specific LLPs. Cost skimping suggests a likely positive relationship between efficiency and general LLP, but also a lagged relationship with NPL because "as time passes,..., the inaction to the loan portfolio becomes apparent" (Berger \& DeYoung, 1997, page 853). Hence, this leads us to posit a dynamic model as previous levels of LLP, through the discretionary component of bank management, has a feedback mechanism to current LLP levels.

The final associated LLP hypothesis states that low efficiency could increase future risk because of moral hazard. In the presence of information asymmetry and agency problems, managers take on more risk which is entirely borne by shareholders and hence engage in risky non-traditional banking services, such subprime lending, to boost profitability (Hughes \& Mester, 1998 and Fiordelisi et al. 2011). Moral hazard could therefore be prevalent when banks in the recent regulatory environment, considered themselves to be systemically important and hence 'too big to fail' (TBTF) ${ }^{2}$.

Finally, it is also of interest to regulators as to why banks counter or pro-cyclically LLP manage risk, where one such hypothesis relates to how LLPs can be used to manipulate earnings by income smoothing and ultimately a bank's share price. With respect to economists, they generally regard income smoothing more positively due to reducing the negative impacts of asset volatility across the business cycle, for example, on bank capital (see Anandarajan et al., 2005). Interestingly, contrariwise to economists, accountants regard income smoothing as financial manipulation (Laeven \& Majnoni, 2003) whereby managers are able to use their own judgement to influence earnings (through the discretionary component of LLP; Bouvatier \& Lepetit, 2008) and hence create problems for shareholders comparing firm profitability and subsequent optimal portfolio share allocations. That is, income smoothing "introduces judgemental modifications to a firm's earnings, that also when not induced by personal managers' objectives, tend to reduce the comparability of results across firms, and may ultimately damage shareholder value” Laeven \& Majnoni (2003), page 197. This, of course, is based on the seminal findings of Litner (1956) in that corporations appear to smooth

\footnotetext{
2 The Royal Bank of Scotland (RBS) was the largest bank globally by total assets in 2008, yet required over $£ 45$ billion in emergency government funding in October of that year in an attempt to remain liquid and maintain stability in the UK banking market. It is widely recognised that the majority of the funds issued by the government were used to cover credit write-downs in the ill-fated recently acquired ABN-Amro subsidiary of the business.
} 
dividends relative to earnings. Indeed, reporting stability concerning income streams can signal cost efficiencies and could affect stock price stability and external rating performance, as well as lowering funding costs and increasing management bonuses and salaries (Bikker \& Metzemakers, 2005). Income smoothing can also distort efficient markets as complete information on the earnings of banks are not fully known or understood by all market participants; leading to arbitrage opportunities for those who know the income-smoothing practices of a particular bank (see, Fonseca and González, 2008 and Leventis et al. 2011). We next present our hypotheses in relation to efficiencies and technological innovative progress.

\section{LLP hypotheses}

\section{Hypothesis 1. Technological Innovative Progress (TIP)}

Our first measure estimates the percentage change in cost of inputs resulting from changes in bank technology. Our so-called TIP measures are obtained from a Stochastic Frontier cost function (details are provided in Supplementary Appendix A) ${ }^{3}$. Following Badunenko \& Kumbhakar (2017) we estimate TIP holding everything else constant in the cost function equal to $T I P=(\partial \ln C / \partial T)$ where "technical change in a cost function is cost diminution over time" (page 796). If $T I P<0$, then bank outputs can be produced at a lower total cost as a result of TIP. Given data and the parameter estimates obtained from the cost function, TIP is incorporated into our specification as an individual bank specific variable, ITIP. In addition, TIP can be further decomposed into a scale biased technological innovative progress along the ray average cost curve $T I P S B=(\partial \ln C / \partial \ln y \partial T)$. If $T I P S B<0$, then for a given product mix, TIP causes larger banks to be more efficient over time than their smaller competitors and hence helps to minimize costs (see, Berger, 2003 and Allen \& Liu, 2007). That is, after the technological change, production at the previously optimal size $(Q)$ is no longer cost minimizing, and bank size has to increase to $Q^{*}$ (where $Q^{*}>Q$ ) in order to minimize ray average costs. In terms of our model, this again is incorporated through individual bank specific estimates, ITIPSB. Given that negative values of TIP (TIPSB) imply technological progress, in order to make the regression equation more intuitive, we decompose the two proxies into two separate dummy variables capturing negative and positive values separately.

\footnotetext{
${ }^{3}$ We use the standard Intermediation approach commonly estimated in the literature, see for example, Williams (2004), Allen \& Liu (2016) Girardone et al. (2009), Wheelock and Wilson (2012) and Bryce et al. (2015). It is not an aim of this paper to delve into a discussion of the input/output debate on bank modelling.
} 
More specifically, the negative dummy variable takes the value of ITIP (ITIPSB) for banks with negative ITIP values (ITIPSB) and zero otherwise. Similarly, we introduce a second dummy that takes the value of ITIP (ITIPSB) for banks with positive ITIP values (ITIPSB) and zero otherwise ${ }^{4}$. These dummies are reported as $\operatorname{ITIP}_{<0}, \operatorname{ITIP}_{>0}$ and $\operatorname{ITIPSB}_{<0}, I$ $T I P S B>0$ respectively.

\section{Hypothesis 2: Bad Management}

We include return on average equity (roae), where performance is used as a proxy for the quality of management. This expands on the NPL models of Louzis et al. (2012) where the authors consider a 'bad management II' hypothesis using return on equity as a proxy for managerial abilities. In LLP modelling ROE is an uncommon variable but it can show that if banks increase loans (holding inputs constant, e.g., monitoring) then they could see an increase in profitability (efficiency) in the short run. However, in the long run they may experience worse bank performance results, ROE therefore serves as a proxy for poor lending abilities which in turn implies increased levels of LLPs. As Louzis et al. (2012) states "performance is negatively associated with increases in future NPLs, ..., by regarding past performance as a proxy for the quality of management" or in our case LLPS (page. 1015). To include bad management in our model is an addition to the LLP literature which so far excludes this relevant variable (see, for example, Anandarajan, Hasan \& Lozano-Vivas 2005; Fonseca and González, 2008; and Leventis et al. 2011).

\section{Hypothesis 3: Income Smoothing}

Bank management may adjust LLPs in order to report stability of income streams over time by increasing (decreasing) the level of LLP when net profits are high (low) in order to minimize variance in earnings. To capture any income smoothing and mitigate for potential endogeneity, we include profit before taxes and provisions scaled by lagged total assets (oprofit) (Skala, 2015). This implies that LLPs could increase during periods of economic growth while they decline throughout economic downturns (Bouvatier \& Lepetit, 2008). As stated above and to recap, this practice could affect market efficiency through increases in asymmetric information between principle and agent. On the other hand, income-smoothing assumes a positive

\footnotetext{
${ }^{4}$ Similar dummy variable has been used by Bouvatier \& Lepetit (2008) to capture non-linearity in the relation between LLP and earnings.
} 
connotation for economists since it can be considered as a tool to reduce asset volatility on bank capital across the business cycle (Laeven \& Majnoni, 2003).

\section{Hypothesis 4: Capital Management}

The capital management hypothesis is tested by the inclusion of total common equity over average assets (equity), in which banks manipulate (general) LLPs in order to maintain a particular capital adequacy ratio under Basel I (Basel Committee, 1987), where general LLP are included in Tier 2, albeit subject to strict limits (see, Agarwal et al. 2007). That is, since there is a potentially high cost associated with raising new capital on the market, especially during economic downturns, there is an incentive for banks to manage their capital ratios using general LLP under Basel I (but less so under Basel II).

\section{Hypothesis 5: Business Cycle}

The business cycle hypotheses are tested in consideration of the significance of macroeconomic $\{$ Macro\} coefficients which includes GDP growth (GDPGR) and unemployment rate $(U N E M P)$. If we find a positive GDP growth and negative unemployment rate coefficients, this indicates pro-cyclical managing of LLPs. These are the standard variables utilized in the literature, see for example, Bikker \& Metzemakers (2005), Bouvatier \& Lepetit (2008) and Bushman \& Williams (2012), Ghosh (2007) and Leventis et al. (2011).

\section{Additional Control Variables and Hypotheses of Interest.}

As is also common in the LLP modelling literature, we include both bank and industry specific control factors which could affect management behavior towards the manipulation of LLPs. The bank specific controls include a dummy variable taking the value of 1 if the bank is listed to the stock exchange (listed) and a size proxy (SIZE) expressed as the log of total assets (Pérez et al. 2008). To capture variation in LLP with respect to loan expansions and increased credit risk while controlling for the non-discretionary component of LLP we include a control variable change in the rate of growth of loans (loansgr). Forward looking provision implies that banks anticipate that loan growth may results in future NPLs and therefore counter cyclically provision against potential loan losses. A negative relationship between loan growth and LLP points towards lack of prudential provisioning strategies under rapid loan expansion, similar to Bikker \& Metzemakers (2005), Fonseca \& González (2008) and Skala (2015). We also include Loans to Deposits (lodep) as a proxy for liquidity and loan coverage by banks. 
In relation to the \{Industry Country Controls\}, we include the industry overall nonperforming loans (INPL) and following Fujii et al. (2018) we add a dummy variable taking the value of 1 if the country belongs to the EU15 group of countries, and zero otherwise (EU15). Finally, we include a dummy that takes the value of 1 for the years 2008-2011 and zero otherwise to capture variations in LLP due to the global financial crisis (crisis) $)^{5}$.

\section{Research design}

As a basis for our LLP specification, we posit a relationship such that LLP becomes a function of previous years' LLPs, and its value at time $t$ is likely to be affected by its lagged term. This general specification is given by equation (1).

$$
L L P_{i t}=\alpha+\sum_{j=1}^{J} \alpha_{j} L L P_{i t-j}+\beta \boldsymbol{X}_{i t}+\eta_{i}+\varepsilon_{i t}
$$

Where, $L L P$ is the ratio of loan loss provisions to average loans (as in Anandarajan, Hasan \& McCarthy 2007), $L L P_{i t-j}$ is the autoregressive component capturing dynamics in the provisioning practices, $\boldsymbol{X}_{i t}$ is the vector of explanatory variables capturing income smoothing, capital management, business cycle, bad management, TIP, and bank specific characteristics; $\eta_{i}$ are individual bank specific effects; and $\varepsilon_{i t}$ is an error term and where the subscripts $i=1, . ., N$ and $t=1, \ldots, T$ denote the cross sectional and time dimensions of the panel. However, given the inclusion of a lagged dependent variable in the equation to be estimated, the conventional panel data estimators are inconsistent since the unobserved panel-level effects are correlated with the lags of the dependent variable. First differencing $(\Delta)$ equation (1) eliminates the individual effects and estimation becomes a straightforward instrumental variables problem, which allows the existence of potentially endogenous right-hand side variables ${ }^{6}$. This general specification is given by equation (2).

$$
\Delta \mathrm{LLP}_{i t}=\sum_{j=1}^{J} \alpha_{j} \Delta L L P_{i t-j}+\beta \Delta \boldsymbol{X}_{i t}+\Delta \varepsilon_{i t}
$$

\footnotetext{
${ }^{5}$ In preliminary analysis we included time fixed effects but were found to be jointly insignificant and consequently we do not include them in the main model. The results were found to be qualitatively the same. The definition for the outset of the global financial crisis follows Curcio et al., (2017). We also included a crisis dummy to capture the years 2008-2014 (and 2009-2014). The results overall remain consistent.

${ }^{6}$ This is the Anderson and Hsiao (1981) estimator where instruments can be constructed in the form of lagged differences or lagged levels.
} 
Arellano \& Bond (1991) propose the use of the Generalized Method of Moments (GMM) procedure taking advantage of all available moment conditions, from which instrumental variables can be drawn from. More specifically, the set of instrumental variables used in the estimation of equation (2) is derived from the following moment conditions, equation (3).

$$
E\left(\boldsymbol{X}_{i t-s} \Delta \varepsilon_{i t}\right)=E\left(L L P_{i t-s} \Delta \varepsilon_{i t}\right)=0 \ldots s>j
$$

The above equation suggests that lagged levels of the lagged dependent, and explanatory variables, are used as instruments for the differenced equation. Arellano \& Bover (1995) and Blundell \& Bond (1998) suggest that variables in levels may be poor instruments for the differenced equation when they are close to a random walk. To mitigate this potential shortcoming, they build a system of equations, consisting of the equation in differences and in levels in a stacked form, equation (4).

$$
\left[\begin{array}{c}
L L P_{i t} \\
\Delta L L P_{i t}
\end{array}\right]=a+\sum_{j=1}^{J} \alpha_{j}\left[\begin{array}{c}
L L P_{i t-j} \\
\Delta L L P_{i t-j}
\end{array}\right]+\beta\left[\begin{array}{c}
\boldsymbol{X}_{i t} \\
\Delta \boldsymbol{X}_{i t}
\end{array}\right]+\varepsilon_{i t}
$$

The above equation can be estimated as a system and Arellano \& Bover (1995) and Blundell \& Bond (1998) suggest using lagged levels as well as lagged differences as instruments; covering any potential weakness arising from the Arellano \& Bond (1991) estimation technique. Formally, these additional orthogonality conditions can be expressed as, equation (5).

$$
E\left[\left(\Delta \boldsymbol{X}_{i t-s}\left(\eta_{i}+\varepsilon_{i t}\right)\right]=E\left[\left(\Delta y_{i t-s}\left(\eta_{i}+\varepsilon_{i t}\right)\right]=0 \ldots s>j\right.\right.
$$

The orthogonality restrictions described in equations (3) and (5) provide the underpinnings of the panel data system GMM (SGMM) estimation. Under the assumption of independent and homoscedastic residuals, consistent parameter estimates can be obtained, while controlling for time-invariant unobserved heterogeneity, simultaneity bias and the aforementioned dynamic relationships.

The majority of empirical studies that have adopted the LLP GMM method also consider the dynamics of bank management in a combined hypothesis testing model; see, for example, Laeven \& Majnoni (2003), Bouvatier \& Lepetit (2008), Fonseca \& González (2008), Bryce et al. (2015) and Olszak et al. (2016). Indeed, our model incorporates jointly, bad management, TIP, income smoothing, capital management and business cycle hypotheses, proposing a new model. This is now the preferred approach and circumvents potential problems on the exclusion of relevant variables in hypothesis testing; see (Anandarajan, Hasan, \& McCarthy, 
2007 and Ghosh 2007). Rewriting equation (1) the specific econometric regression takes the following form, equation (6),

$$
\begin{aligned}
& L L P_{i t}=\text { const }+\alpha_{j} \sum L L P_{i t-j}+\beta_{1} \text { oprofit }_{i t}+\beta_{2} \text { equity }_{i t}+\beta_{3} \text { loangr }_{i t}+{ }_{(6} \\
& +\beta_{5} \text { roae }_{i t}+\beta_{6,7}\left\{\operatorname{ITIP}(S B)_{<0 ; i t}\right\}+\beta_{8,9}\{\operatorname{ITIP}(S B)>0 ; i t\}+ \\
& +\delta_{1,2}\{\text { Bank Specific Controls } i t\}+\delta_{3,4}\{\text { Industry Country ( ) }
\end{aligned}
$$

In equation (6), the subscripts $i$ and $t$ denote the bank and time dimension of the panel data (we further omit these notations for simplicity). In relation to the variables included in the model, lagged values of the dependent variable capture the autoregressive component in the emergence of doubtful loans, or time series persistency (see Packer \& Zhu, 2012). These lags give therefore a closer approximation to the potential impact of stock variables on LLP at time $t$ and lessens the potential problems related to omitted variables (Laeven \& Majnoni, 2003). The introduction of lags of the dependent variable also takes into account a change in the speed of adjustment of loan loss provisions and "captures adjustment costs that constrain complete adjustment to an equilibrium level" (Fonseca \& González, 2008, page 221). The remaining explanatory variables follow the discussion on Section 3 with their associated hypotheses.

\section{The data}

Bank-level data was downloaded from BankScope (Fitch-IBCA) over the period 2002 to 2014, hence beginning at the introduction of Euro note circulation $(€)$, with industry/macroeconomic variables obtained from World Bank and SNL Financial. A similar sample period has also been used in Fujii et al. (2018), but the sample of banks has been decreased due to missing data in the dependent variable LLP. Finally, McKee \& Kagan, (2018) also utilize a data set ending in 2014 in a study of US community banks. The sample is constructed based on the following rationale; firstly, we are interested in how banks based in member states behave in local markets with respect to LLPs and are therefore not individually influenced by cross-border management behavior from non-domestic bank holding companies located in another jurisdiction - which of course could be found under a consolidated sample?

\footnotetext{
${ }^{7}$ For example, the European Central Bank supervised entity list shows banks which are supervised on the grounds of different 'significant asset size' starting from a bottom class of $€ 30$ to $€ 50$ billion. For example, in terms of the Spanish bank Banco Santander S.A. (size class above $€ 1,000$ billion) it has individual 'significant size presence' in Spain, Portugal, Austria, Belgium Germany, Italy and Luxemburg. Whereas, the French bank BNP Paribus (size class above $€ 1,000$ billion) has individual 'significant size presence' in France, Austria, Belgium, Germany, Italy, Luxemburg, The Netherlands and Portugal. Hence, the use of consolidated accounts could muddy the water
} 
We therefore follow the methodology of the 'SYMBOL' bank stress testing risk assessments published by the European Commission that models risk associated with non-performing loans using only unconsolidated data (Benczur et al., 2017 also follows this procedure). The final sample consists of 450 commercial banks with 3.145 observations, operating in 26 European countries. Table 1 presents the summary statistics of the variables used in our dynamic SGMM for the full sample. (a detailed discussion on the frequency distributions of banks per country and year and a description of asset size classes can be found in Supplementary Appendix B).

\section{INSERT TABLES $1 \& 2$ HERE}

Table 2 presents the correlation matrix for the explanatory variables used in the regression. None of the bank specific variables exhibit very high correlations therefore mitigating any multicollinearity concerns. With respect to the macroeconomic and industry variables, we observe that the reported correlations follow the theoretical expectations and the highest correlation is reported between the unemployment rate (UNEMP) and industry non-performing loans (INPL), 0.576 (significant at the 5\% level). In terms of insignificance - only 15 pairwise correlations were found to show an insignificant relationship between the variables. We next present our results.

\section{Empirical results}

\subsection{Technological Innovative Progress (TIP) Results}

Table 3, Panel A reports the results of TIP for each of the 5 quintiles (asset classes) in which frequency indicates the number of banks within each quintile that are negative and significantly different from zero. With respect to the results we observe that $38.51 \%$ of banks experienced overall TIP. In addition, the different subgroups indicate that quintiles 2, 3 and 4 (the small, medium and large banks respectively) experienced greater cost reductions due to TIP than the average sized banks. For example, with respect to quintile 2 (small banks with assets between

concerning which country management risk practice is used overall, say in the home country (Spain or France) against its overseas banks in constituent countries within the European Union. An unconsolidated approach is therefore deemed best to determine the characteristics at the individual country level instead of a Bank Holding Company approach (consolidated) which could not differentiate across and between these interesting country specific management LLP difference practices - again based on the EU SYMBOL approach to analysing banks. 
$€ 280$ million and $€ 669$ million) had a TIP equal to $51.51 \%$ and quantile 3 (medium asset sized banks $€ 670$ million to $€ 1,291$ million) had the largest TIP equal to $65.82 \%$.

These results show that the small and medium banks appear to be statistically more innovative due to technological change than the largest banks (quintile 5 equal to $11.61 \%$ ). An explanation for these results is that small and medium sized banks innovate at a faster rate than the largest banks (quintile 5) as the latter can rely on a large customer based and branch network - exploiting market power for profitability. Whereas, smaller banks rely on being agile in the face of innovation to counteract scale inefficiencies (being too small in asset size) to fund operations, reduce capital costs, and implement new technologies to reduce costs.

Interestingly our finding is an update to Berger \& Deyoung (2003), who in their analysis between the relationship of the largest MBHCs to smaller affiliates, find that "MBHCs apply some of the hard-information techniques to small bank affiliates for the first time, yielding substantial increases in control over these affiliates" (p. 1507) and as such the smallest banks had greater TIP. As we only consider unconsolidated banks our results indicate a standalone size effect of small and medium size asset banks and not a relationship where the largest banks force cost efficiencies on smaller banks through their own innovations. Our results could also show that the smaller banks are playing TIP catch-up with their larger competitors.

With respect to the scale biased results our findings show that overall TIPSB also increased, equal to $44.07 \%$, but this effect is largest in relation to quintiles 1, 2 and 3 and as such these banks were able to increase their efficient size due to TIP (Table 3, Panel B) and hence again reduce costs. The smaller and medium size banks were able to expand operations (outputs) faster than the largest banks due to the introduction of new technology (additional discussion on the distributions of TIP(SB) for different asset sizes can be found in Supplementary Appendix C).

\section{INSERT TABLE 6}

Figure 1 (Panels A and B) shows the distributions of TIP and TIPSB in the pre and postcrisis periods (we follow Curcio \& Hasan (2015) and define 2008 as the beginning of the crisis). The vertical lines represent the median of the distribution and values less than zero indicate technological progress. In all panels the thin solid line represents no technological progress. With respect to TIP we observe that banks relied on innovations to reduce their costs more during than after the crisis period (2008-2014). Indeed, we observe a shift in the density distribution towards the left in the post-crisis period. These results compare nicely with 
Badunenko \& Kumbhakar (2017) who found positive technological progress for state banks equal to $2 \%$, and foreign banks equal to $8 \%$ which then declined to $0 \%$ after re-regulations in India. The difference between the results is that we consider GFC whereas Badunenko \& Kumbhakar (2017) review changes in Indian bank regulations. Furthermore, with respect to TIPSB, we note that banks experience size increases due to innovations both in the pre and the post-crisis periods. However, this effect is stronger in the pre-crisis period (represented by the thin-dotted line on the left of the graph) as the post-crisis distribution shifts to the right after 2008 (represented by the long-dash distribution).

\section{INSERT FIGURE 1}

The above observations are further examined by presenting only the distributions of the banks that experienced a significant TIP result (Figure 2). Panel A shows this distribution with respect to those banks that exhibit reductions in cost due to technological progress. The postcrisis distribution has a longer left tail than the pre-crisis, indicating greater TIP for the years after the crisis.

\section{INSERT FIGURE 2 HERE}

We find that banks increased technological innovations after the crisis by implementing new loan controls, whilst adjusting risk management process through innovations and regulation (for a discussion of changes in risk regulations during our sample period and how banks changed their operations see a recent IMF report, Adrian, 2018). Whereas, Panel B shows the results for the TIPSB and as noted above, the scale effects due to technological innovations fade away in the post-crisis period as the distribution (solid line, Panel B) has shorter left tail, with a higher negative median.

\subsection{Results from dynamic LLP Model.}

We estimate a first order dynamic panel data model, following the Arellano \& Bond (1991), Arellano \& Bover (1995) and Blundell \& Bond (1998) method of a two-step system GMM estimator $(\mathrm{SGMM})^{8}$. In our model we assume that all macroeconomic/industry control

\footnotetext{
${ }^{8}$ To ensure dynamic completeness, we estimate four (4) auxiliary regressions with different subsets of LLP lags.
} 
variables are strictly exogenous to individual banks. On the other hand, with respect to the bank specific variables, prior literature does not offer conclusive evidence as to whether or not LLP determinants should be treated as endogenous or exogenous (Skala, 2015). From an economic perspective, endogeneity may arise due to simultaneous determination of LLP and any of the explanatory bank specific variables. For example, LLP and innovations could be simultaneously determined and the direction of correlation could run from LLP to TIP (TIPSB ). That is, if we assume technological innovations are endogenous choice variables for banks and their levels are chosen so as to optimize the reported levels of LLP at $t$, then the reported LLP levels may in turn effect the future level of innovations that banks are willing to attain? The implication will be a causal effect from the dependent variable to bank innovations. In this case, LLP and technological innovations are simultaneously determined and TIP and TIPSB should be treated as endogenous regressors and appropriate IVs be constructed and used in estimation. We reject the null hypothesis of a strict exogeneity test (Wooldridge, 2001), confirming that bank innovations are dynamically endogenous to LLP ${ }^{10}$.

In determining consistency across the SGMM estimator and following prior literature (Baum, Schaffer, \& Stillman, 2003), two post estimation tests are conducted; the Hansen test of joint validity of the instruments and the second order serial correlation (Arellano - Bond), in order to evaluate the correct specifications of the models. The Hansen over identification test confirmed the validity of our instruments and the absence of correlation between the instruments used and the error term in the models (we fail to reject the null hypotheses in all of the model specifications). It should be noted there is no clear rule as to the optimal number of instruments that should be included in a GMM estimator. However, the proposal by Roodman (2009a) concerning the number of instruments and the Hansen J-test p-values are followed. For example, in Model 1, the number of instruments (442) does not exceed the number of groups (450). Second, the p-values obtained from the Hansen J-statistic equal 0.516. In addition, we investigate the relevance of the SGMM instruments based on underidentification tests, following Wintoki, Linck \& Netter (2012) (these tests are discussed in more detail in Supplementary Appendix C). Furthermore, we confirm the validity of the SGMM by

\footnotetext{
We chose the preferred lag specification on the basis of Akaike's/Schwarz's Bayesian information criteria and a Vuong (1989) test. Results are available upon request.

${ }^{9}$ This process is subject to income smoothing, capital management and pro/counter cyclical provisioning purposes, among others - as implied by equation (6).

10 Further lag analysis where we regress the current levels and changes of these levels of the bank specific variables on LLP lags, suggests that previous year's LLP levels are negatively (positively) related to levels of $I T I P<0($ ITIPSB $<0)$, confirming the findings of the strict exogeneity test. Results of the strict exogeneity and lag analysis tests are available upon request.
} 
rejecting the null of no first order serial correlation $A R(1)$ and we fail to reject the null hypothesis of no second order serial correlation $A R(2)$; which indicates a correct model specification. Finally, the finite sample correction proposed by Windmeijer (2005) is implemented, calculating corrected standard errors.

\subsubsection{Discussion of results}

With respect to the empirical findings, we present results from different estimators that operate under different assumptions. More specifically, we report findings from static OLS/fixed-effects regressions, dynamic OLS and SGMM ${ }^{11}$. The estimated coefficients from the regressions are presented in Table 4. The results suggest that the LLP ratio is a positive function of its own lag, with significant coefficients equal to 0.28 to 0.58 (columns [1] and [2]). One insight from the dynamic OLS is the importance of past levels of LLP in explaining variations in its current levels (the $R^{2}$ increases from 0.18 in the static OLS to 0.62 in the dynamic). This finding suggests that banks are likely to increase their loan provisions if they have already made provisions in the previous year.

\section{INSERT TABLE 4}

\section{Hypothesis 1: Technological Innovative Progress (TIP)}

With respect to TIP, one insight that becomes clear is that in the absence of technological progress, there is no effect on banks' LLP levels $($ ITIP $>0$ and ITIPSB $>0$ are insignificant across all 4 models). However, banks that experience technological progress observe two different results. First, ITIP $<0$ is negative and significant in both dynamic models. It is therefore apparent that as banks extend their innovative and technological capabilities with respect to LLP - through their abilities to determine delinquent and problem loans via new innovations - costs decrease through TIP. These reductions could occur from changes in bank's use of better computer risk modelling systems and also regulation - an addition to standard cost efficiencies (see, Adrian, 2018). Even though we find evidence of bad management (hypothesis 4), banks can potentially reduce the costs associated with their bad management

\footnotetext{
${ }^{11}$ Prior literature has estimated both static and dynamic LLP specifications. For example, Leventis et al., (2012) and Curcio \& Hasan, (2015) estimate static models; Bouvatier et al., (2014) estimate a dynamic regression and Laeven \& Majnoni (2003) and Curcio et al., (2017) estimate both.
} 
practices through the advancing TIP. That is, improving technology mitigates the impact of bad management. ${ }^{12}$

When taking into account the effect that technological innovations have had on the asset size of banks, we observe that ITIPSB $<0$ is positive and significant. This result suggests one of two things, firstly, as bank's cost minimizing scale of outputs increases due to innovations in technology (for example, capturing more markets with new products or geographical expansion thereby increasing lending), banks show an ability to recognize additional risk (see Hunter \& Timme, 1991, page 339). They are then able to service the LLP book through the introduction of advanced implementation of computer risk management systems on the loan portfolio (Hunter \& Timme, 1991, call this 'production innovations'), leading to higher levels of LLPs. Or, secondly, banks which experience changes in their cost minimizing output scale, report higher LLPs when at the same time report higher pre-provisioning profits, thus strategically amplifying their income smoothing practices. This could show a link between income smoothing and ITIPSB. For example, the smallest asset sized banks experience greater scale changes due to technological innovations. Therefore, if the second hypothesis holds, we would expect to find that smaller banks would be more prone to income smoothing. In untabulated results we further test this size hypothesis by re-estimating equation (6) and including an interaction term between oprofit and a size dummy (taking the value of 1 for banks that belong to the first 3 quintiles and zero otherwise). The estimated coefficient of the interaction term is positive but insignificant, offering no support in favor of aforementioned size hypothesis. All other estimated coefficients remain qualitatively similar to the reported ones in Table $4^{13}$.

\section{Hypothesis 2: Bad Management}

We find a negative and significant roae coefficient in all 4 models thereby showing that European banks exhibit bad management by skimping on monitoring and thereby reducing future earnings by diverting cash resources (or profits/dividends) to bolster LLPs in the future to cover bad decisions in the past (also corroborating Louzis et al. 2012). That is, generally, European bank managers show poor abilities to monitor their loan portfolios and offer loans to

\footnotetext{
${ }^{12}$ We also tested the interaction term between roae and ITIP $<0$ and roae and ITIPSB $<0$ (those banks which experienced improvements in technology). Both coefficients on these interaction terms were found to be positive yet insignificant, while the individual effects of roae, ITIP $<0$ and ITIPSB $<0$ remained the same and significant as the current model discussed in this section (results are not presented to save space).

${ }^{13}$ We also used a dummy taking the value of 1 for banks that are smaller than the median of the log of total assets and the results still hold. The interaction term coefficient was positive but still insignificant.
} 
people who are likely to default in the event of a macroeconomic downturn. This result ties in nicely with the negative and significant relationship between GDPGR and LLP explained in the business cycle hypothesis.

\section{Hypothesis 3: Income Smoothing}

The income-smoothing hypothesis concerns the relationship between net income (oprofit) and LLP, where we find a significant positive relationship in all estimated regressions (the coefficient ranges from 0.478 in the SGMM to 0.231 in the dynamic OLS). This finding is similar to the results across 40 countries by Fonseca and González (2008), European banks by Leventis et al. (2011), South East Asian countries by Packer \& Zhu (2012), central European banks by Skala (2015) and US banks by Balasubramanyan et al. (2016). Such that, "regardless of the commendable or condemnable motives underlying income smoothing" (as shown by a positive relationship) "this behavior contributes to financial soundness of banks and reduces procyclicality" (page. 150, Bikker \& Metzemakers, 2005). In addition, the drop in the estimated coefficient of oprof it when moving from the static OLS to the dynamic OLS implies that current pre-provisioning profits are correlated with past LLP levels, suggesting a potentially endogenous relationship. When controlling for endogeneity and fixed effects under a SGMM, we note that the estimated coefficient doubles in magnitude (equal to 0.4780, Table 4, column [1]). This result therefore suggests that ignoring endogeneity and LLP dynamics could understate the economic significance of income smoothing. Therefore, if oprofit is thought to have at least a predetermined effect on LLP then a SGMM approach should be estimated.

\section{Hypothesis 4: Capital Management}

With respect to the capital management hypothesis, equity the sign of the estimated coefficient remains unchanged across all models (negative), but its significance changes in the static fixed-effects model (significant at the 10\%). However, this significance could be an artifact of endogeneity as previous years LLPs are related to levels and hence changes in levels of equity. That is, when taking into account bank specific effects and endogeneity in the SGMM, the results indicate that European banks do not boost their Tier 2 capital positions using LLPs, and as such, do not suffer from a "banking system capitalization (problem, which) is a barrier to business cycle vulnerability" (Glen \& Mondragón-Vélez, 2011, page 158, our 
italics). A result also found for Indian banks by Ghosh (2007) and European banks by Leventis et al. (2012).

\section{Hypothesis 5: Business Cycle}

We find that there is a negative and significant relationship with GDPGR (GDP growth) ranging from -0.0477 in the GMM model, to -0.0292 in the static OLS model. Therefore, European banks did not undertake 'forward looking' provisioning, a result corroborated by the negative association between credit growth (loangr) and LLP. The implication is that when loan portfolios expand during booms, managers decrease reserves, thus not accounting for possible future losses. This result corresponds favorably with the implementation of IAS39 across Europe. Implying that objective evidence is required on loan impairments before loan loss provisions can be made, hence restricting buffering across the economic cycle and exacerbating pro-cyclical LLP.

In addition, Craig (2005) observes that banks in developed countries (i.e., Australia, Hong Kong, Japan, New Zealand and Singapore) generally show a tendency of assessing risk over relatively short horizons, leading them to under-estimate risk during boom periods while overestimating the risk during economic downturns. If this was also to be true for European banks our results explain the cancelling out of LLP across the business cycle. However, as Skala (2015) notes, our finding "prompts the question of whether the reserves that central European banks established during economic booms are sufficient" (page. 35). Furthermore, this result could of course be due in part to overriding macroeconomic conditions in our sample period. That is, there was no need to forward provision as banks had different risk management behavior characteristics. To this end, the unemployment rate (UNEMP) is found to be insignificant with respect to LLP in all models, see also Bikker \& Metzemakers (2005) and Olszak et al. (2016). A possible explanation here, is that the unemployment rate does not act as a proxy for loan demand (Beatty \& Liao, 2011). The effect of unemployment is therefore minimal and hence we find an insignificant relationship between the unemployment rate, bank lending and LLPs. This relationship between unemployment and LLP is not a forward-looking relationship, but a current reactionary co-movement: unemployment increases $\rightarrow$ loan defaults increases $\rightarrow$ LLP increases.

\section{Additional Control Variables and Hypotheses of Interest}


In addition, our findings highlight that INPL (industry non-performing loans) and lodep (loans to deposits) do not have significant effects on LLPs, and therefore, industry bank characteristics and individual bank liquidity constraints do not override risk management behavior characteristics. Interestingly, in all specifications there is a negative and significant link between the EU15 status and loan provisions. That is, ceteris paribus, banks who operate in the EU15 countries provision less for bad loans, with respect to their non EU15 counterparts. The projected LLP values from the estimated SGMM regression for non EU15 and EU15 countries are $0.0120^{* * *}$ and $0.0096^{* * *}$ respectively ${ }^{14}$. With respect to the additional control variables, the dummies listed (those banks which are listed on their domestic stock exchanges) and crisis (the global financial crisis of 2008) are both insignificant. Finally, with respect to the control variable $S I Z E$, this has a negative effect on LLP in all models, indicating that the largest European banks report lower LLPs suggesting that their credit portfolio diversification leads them to report lower provisioning levels.

\subsubsection{Additional analyses}

Table 5 presents 3 additional SGMM specifications that consider whether our results are stable if we exclude ITIP and ITIPSB, analyse post crisis income smoothing and also a nonlinear income smoothing model following Balboa, López-Espinosa, \& Rubia, 2013. In terms of our first robustness check, in Model 1, we can see that removing ITIP and ITIPSB has no effect on all the hypotheses 1 to 5 above, everything holds albeit we do note that SIZE and crisis now become significant. Given that crisis could potentially offer an insight, we again re-estimate our main SGMM but now Model 2 controls for increased income smoothing during the financial crisis (see for example, Curcio, De Simone, \& Gallo, 2017). To investigate for increased income smoothing during the crisis, relative to the pre-crisis period, we include an interaction term crisis $\times$ oprofit. Column [2] in Table 5 reports the estimated coefficients. Most of the estimated coefficients remain similar to those reported in Table 4 column 1, however the EU15 dummy turns insignificant. With respect to crisis $\times$ oprofit, a one-sided t-test does not confirm the hypothesis that banks have smoothed their income via LLPs more intensively during or after the crisis.

\section{INSERT TABLE 5}

\footnotetext{
$1495 \%$ confidence intervals were estimated using the Delta method, where ${ }^{* * *}$ indicates significance at the $1 \%$.
} 
The third set of additional analysis considers a potential non-linear effect of income smoothing, as incentives to smooth income may be dependent of the relative size of earnings (see, Balboa, López-Espinosa, \& Rubia, 2013). In this latter case we generate a dummy variable (doprofit) taking the value of oprofit for banks reporting pre-provisioning earnings greater than the annual $75^{\text {th }}$ percentile and zero otherwise ${ }^{15}$. In Model 3 we find that the coefficient of dprofit is positive and significant at the $1 \%$, indicating that the best performing EU banks are more prone to report higher LLPs when earnings are high (Table 5, Column [2]). Once again we find that all hypotheses 1 to 5 are unaffected and the remaining coefficients maintain their sign and significance in line with Table 4, Column [1].

\section{Conclusions}

In the banking loan loss provisioning literature there has been widely different reported managerial behavior characteristics including; income smoothing, capital management, business cycle theory, and bad management hypotheses. The latter's effect can originate from three sources of inefficiency; cost, technological innovative progress (TIP) and scale based TIP (TIPSB). We present a coherent and fully specified dynamic models that find both bad management, TIP and TIPSB are endogenous with respect to LLP risk management behavior. That is, previous studies which have only explicitly allocated banks' income smoothing, capital management as the internal change characteristic in provisioning behavior could be misspecified through the exclusion of bad management, TIP and TIPSB.

With respect to our results we find that $38.51 \%$ of banks experienced overall TIP but that small banks with assets between $€ 280$ million and $€ 669$ million had a TIP equal to $51.51 \%$ and medium asset sized banks $€ 670$ million to $€ 1,291$ million had the largest TIP equal to $65.82 \%$. These results show that small and medium asset sized banks are more innovative due to technological progress than the largest banks (assets greater than $€ 3,137$, TIP equal to $11.61 \%$ ). In addition, when we consider scale biased effects, again the smallest banks show the largest TIPSB equal to $58.51 \%$ whereas the largest banks showed the smallest TIPSB equal to $20.51 \%$.

\footnotetext{
${ }^{15}$ This dummy is a variation used by Bouvatier \& Lepetit (2008) as here we are interested in identifying the best performing banks in our sample and not simply the ones reporting positive earnings. We also control for nonlinearity in the earning's smoothing around the zero threshold by including a dummy variable taking the value of oprofit in the case of positive earnings before provisions and taxes, and zero otherwise. The results are qualitatively similar to the ones reported in Table 9, Column [3] so we do not present them here. Including both oprofit and dprofit led to VIF values of 85.68 and 85.24 respectively, thus we chose not include both variables together.
} 
That is, ceteris paribus, the larger banks have smaller scale TIPSB efficiencies relative to smaller banks and therefore smaller to medium banks see larger cost efficiencies in the introduction of new technologies.

The main findings associated with our new LLP model show that as banks extend their innovative and technological capabilities with respect to LLP, costs decrease through TIP. These reductions could occur from changes in bank's use of better risk modelling of their loan portfolios and also through new regulations such as Basel capital requirement directives. In addition, even though we find bad management practice, banks can potentially reduce these costs through advancing TIP. That is, the introduction of new technology and the improvements that it brings mitigates the impact of bad management and its associated cost inefficiencies.

With respect to the traditional LLP hypotheses, we concur that banks income smooth, although profits are correlated with past LLP levels, suggesting a potentially endogenous relationship. European banks do not boost their Tier 2 capital positions using LLPs, and as such, do not suffer from a banking system capitalization. Further, these banks did not undertake 'forward looking' provisioning, a result corroborated by the negative association between credit growth and LLP. Finally, we find that the macro environment had little to no effect as European banks did not undertake 'forward looking' provisioning corresponding favorably with the implementation of IAS39 across Europe limiting the pro-cyclical nature of LLPs. 


\section{References}

Adrian, T. (2018). Risk Management and Regulation. International Monetary Fund, 18(13), $1-44$.

Agarwal, S., Chomsisengphet, S., Liu, C., \& Ghon Rhee, S. (2007). Earnings management behaviors under different economic environments: Evidence from Japanese banks. International Review of Economics and Finance, 16(3), 429-443.

Allen, J., \& Liu, Y. (2007). Efficiency and economies of scale of large Canadian banks. Candian Journal of Economics, 40(1), 225-244.

Anandarajan, A., Hasan, I., \& Lozano-Vivas, A. (2005). Loan loss provision decisions: An empirical analysis of the Spanish depository institutions. Journal of International Accounting, Auditing and Taxation, 14(1), 55-77.

Anandarajan, A., Hasan, I., \& McCarthy, C. (2007). Use of loan loss provisions for capital, earnings management and signalling by Australian banks. Accounting and Finance, 47(September 2004), 357-379.

Anderson, T. W., \& Hsiao, C. (1981). Estimation of Dynamic Models with Error Components. Journal of the American Statistical Association, 76(375), 598.

Arellano, M. (1993). On the testing of correlated effects with panel data. Journal of Econometrics.

Arellano, M., \& Bond, S. (1991). Some tests of specification for panel data: Monte Carlo evidence and an application to employment equations. The Review of Economic Studies.

Arellano, M., \& Bover, O. (1995). Another look at the instrumental variable estimation of error-components models. Journal of Econometrics, 68(1), 29-51.

Badunenko, O., \& Kumbhakar, S. C. (2017). Economies of scale, technical change and persistent and time-varying cost efficiency in Indian banking : Do ownership, regulation and heterogeneity matter? European Journal of Operational Research, 260, 789-803.

Balasubramanyan, L., Thomson, J. B., \& Zaman, S. (2016). Evidence of Forward-Looking Loan Loss Provisioning with Credit Market Information. Journal of Financial Services Research.

Balboa, M., López-Espinosa, G., \& Rubia, A. (2013). Nonlinear dynamics in discretionary accruals: An analysis of bank loan-loss provisions. Journal of Banking \& Finance, 37(12), $5186-5207$.

Basel Committee on Banking Supervision. (2004). International Convergence of Capital Measurement and Capital Standards: A Revised Framework.

Baum, C., Schaffer, M., \& Stillman, S. (2003). Instrumental variables and GMM: Estimation 
and testing. Stata Journal, 3(1), 1-31. Retrieved from http://www.stata.com/meeting/2nasug/wp545.pdf

Beatty, A., \& Liao, S. (2011). Do delays in expected loss recognition affect banks' willingness to lend? Journal of Accounting and Economics, 52(1), 1-20.

Benczur, P., Cannas, G., Cariboni, J., Di Girolamo, F., Maccaferri, S., \& Petracco Giudici, M. (2017). Evaluating the effectiveness of the new EU bank regulatory framework: A farewell to bail-out? Journal of Financial Stability, 33, 207-223.

Berger, A. N. (2003). The Economic Effects of Technological Progress: Evidence from the Banking Industry. Journal of Money, Credit, and Banking, 35(2), 141-176.

Berger, A. N., \& Deyoung, R. (2003). Technological Progress and the Geographic Expansion of the Banking Industry. Journal of Money Credit and Banking, 38(6), 1483-1513.

Berger, A. N., \& DeYoung, R. (1997). Problem loans and cost efficiency in commercial banks. Journal of Banking \& Finance, 21(6), 849-870.

Bikker, J. a., \& Metzemakers, P. a. J. (2005). Bank provisioning behaviour and procyclicality. Journal of International Financial Markets, Institutions and Money, 15(2), 141-157.

Blundell, R., \& Bond, S. (1998). Initial conditions and moment restrictions in dynamic panel data models. Journal of Econometrics, 87(1), 115-143.

Bouvatier, V., \& Lepetit, L. (2008). Banks' procyclical behavior: Does provisioning matter? Journal of International Financial Markets, Institutions and Money, 18(5), 513-526.

Bouvatier, V., Lepetit, L., \& Strobel, F. (2014). Bank income smoothing, ownership concentration and the regulatory environment. Journal of Banking \& Finance, 41, 253270.

Bryce, C., Dadoukis, A., Hall, M., Nguyen, L., \& Simper, R. (2015). An analysis of loan loss provisioning behaviour in Vietnamese banking. Finance Research Letters, 14, 69-75.

Bushman, R. M., \& Williams, C. D. (2012). Accounting discretion, loan loss provisioning, and discipline of Banks' risk-taking. Journal of Accounting and Economics, 54(1), 1-18.

Curcio, D., De Simone, A., \& Gallo, A. (2017). Financial crisis and international supervision: New evidence on the discretionary use of loan loss provisions at Euro Area commercial banks. British Accounting Review, 49(2), 181-193.

Curcio, D., \& Hasan, I. (2015). Earnings and capital management and signaling: the use of loan-loss provisions by European banks. The European Journal of Finance, 21(1), 26-50.

Drake, L., \& Simper, R. (2002). Economies of scale in UK building societies: A re-appraisal using an entry/exit model. Journal of Banking and Finance, 26(12), 2365-2382.

Fiordelisi, F., Marques-Ibanez, D., \& Molyneux, P. (2011). Efficiency and risk in European 
banking. Journal of Banking \& Finance, 35(5), 1315-1326.

Fonseca, A. R., \& González, F. (2008). Cross-country determinants of bank income smoothing by managing loan-loss provisions. Journal of Banking \& Finance, 32(2), 217-228.

Fujii, H., Managi, S., Matousek, R., \& Rughoo, A. (2018). Bank efficiency, productivity, and convergence in EU countries: a weighted Russell directional distance model. The European Journal of Finance, 24(2), 135-156.

Fukuyama. H and Weber. W. (2015). Nonperforming Loans in the Bank Production technology. In Quantitative Financial Risk Management (pp. 46-70).

Ghosh, S. (2007). Loan loss provisions, Earnings, Capital management and signalling: Evidence from Indian Banks. Global Economic Review, 36(2), 121-136.

Girardone, C., Nankervis, J. C., \& Velentza, E.-F. (2009). Efficiency, ownership and financial structure in European banking: A cross-country comparison. Managerial Finance, 35(3), $227-245$.

Glen, J., \& Mondragón-Vélez, C. (2011). Business cycle effects on commercial bank loan portfolio performance in developing economies. Review of Development Finance, 1(2), $150-165$.

Hughes, J. P., \& Mester, L. J. (1998). Bank Capitalization and Cost: Evidence of Scale Economies in Risk Management and Signaling. Review of Economics and Statistics, $80(2), 314-325$.

Hunter, W. C., \& Timme, S. G. (1991). Technological Change in Large U . S . Commercial Banks *. The Journal of Business, 64(3), 339-362.

John Litner. (1956). Distribution of Incomes of Corporations Among Dividends, Retained Earnings , and Taxes. The American Economic Review, 46(2), 97-113.

Kalyvas, A. N., \& Mamatzakis, E. (2014). Does business regulation matter for banks in the European Union? Journal of International Financial Markets, Institutions and Money, $32(1), 278-324$.

Laeven, L., \& Majnoni, G. (2003). Loan loss provisioning and economic slowdowns: Too much, too late? Journal of Financial Intermediation, 12(2), 178-197.

Leventis, S., Dimitropoulos, P. E., \& Anandarajan, A. (2012). Signalling by banks using loan loss provisions: the case of the European Union. Journal of Economic Studies, 39(5), 604618.

Leventis, S., Dimitropoulos, P. E., Anandarajan, A., Leventis, S., Dimitropoulos, P. E., \& Anandarajan, A. (2011). Loan Loss Provisions, Earnings Management and Capital Management under IFRS: The Case of EU Commercial Banks. J Financ Serv Res, 40, 
$103-122$.

Liu, S. T. (2010). Measuring and categorizing technical efficiency and productivity change of commercial banks in Taiwan. Expert Systems with Applications, 37(4), 2783-2789.

Louzis, D. P., Vouldis, A. T., \& Metaxas, V. L. (2012). Macroeconomic and bank-specific determinants of non-performing loans in Greece: A comparative study of mortgage, business and consumer loan portfolios. Journal of Banking \& Finance, 36(4), 1012-1027.

Mamatzakis, E., Kalyvas, A. N., \& Piesse, J. (2013). Does Regulation in Credit, Labour and Business Matter for Bank Performance in the EU-10 Economies? International Journal of the Economics of Business, 20(3), 341-385.

McKee, G., \& Kagan, A. (2018). Community bank structure an X-efficiency approach. Review of Quantitative Finance and Accounting, 51, 19-41.

Olszak, M., Pipień, M., Kowalska, I., \& Roszkowska, S. (2016). What Drives Heterogeneity of Cyclicality of Loan-Loss Provisions in the EU? Journal of Financial Services Research, 1-42.

Packer, F., \& Zhu, H. (2012). Loan loss provisioning practices of Asian banks (BIS Working Paper No. 375). Retrieved from www.bis.org

Pérez, D., Salas-Fumás, V., Saurina Banco de España, J., Pé Rez Ã, D., Salas-fum Ã, V. S., \& Saurina Ã, J. S. (2008). Earnings and Capital Management in Alternative Loan Loss Provision Regulatory Regimes Earnings and Capital Management in Alternative Loan Loss Provision Regulatory Regimes. European Accounting Review, 173(907469330), $423-445$.

Roodman, D. (2009a). A Note on the Theme of Too Many Instruments. Oxford Bulletin of Economics and Statistics, 71(1), 135-158.

Roodman, D. (2009b). How to do xtabond2: An introduction to diffrence and system GMM in Stata. The Stata Journal, 9(1), 86-136.

Skala, D. (2015). Saving on a rainy day? Income smoothing and procyclicality of loan-loss provisions in Central European Banks. International Finance, 18(1), 25-46.

Staikouras, C., Mamatzakis, E., \& Koutsomanoli-Filippaki, A. (2008). Cost efficiency of the banking industry in the South Eastern European region. Journal of International Financial Markets, Institutions and Money, 18(5), 483-497.

Vuong, Q. H. (1989). Likelihood Ratio Tests for Model Selection and Non-nested Hypotheses. Econometrica, 57(2), 307-333. Retrieved from https://econpapers.repec.org/RePEc:ecm:emetrp:v:57:y:1989:i:2:p:307-33

Wheelock, D. C. D., \& Wilson, P. W. (2012). Do large banks have lower costs? New estimates 
of returns to scale for US banks. Journal of Money Credit and Banking, 44(1), 171-199. Williams, J. (2004). Determining management behaviour in European banking. Journal of Banking and Finance, 28(10), 2427-2460.

Wintoki, M. B., Linck, J. S., \& Netter, J. M. (2012). Endogeneity and the dynamics of internal corporate governance. Journal of Financial Economics, 105(3), 581-606.

Wooldridge, J. M. (2001). Econometric Analysis of Cross Section and Panel Data. The MIT Press, 735. 
Table 1. Summary Statistics

\begin{tabular}{llllll}
\hline \hline Variable & Observations & Mean & Std. Dev. & Min & Max \\
\hline \hline LLP & 3,145 & 0.0101 & 0.0314 & -0.2610 & 1.2379 \\
oprofit & 3,145 & 0.0151 & 0.0172 & -0.0531 & 0.7081 \\
equity & 3,145 & 0.0999 & 0.0718 & -0.0029 & 0.8620 \\
loansgr & 3,145 & 0.0772 & 0.3085 & -0.9879 & 8.7691 \\
GDPGR & 3,145 & 0.0121 & 0.0330 & -0.1481 & 0.1190 \\
UNEMP & 3,145 & 0.0818 & 0.0326 & 0.0340 & 0.2720 \\
roe & 3,145 & 0.0624 & 0.2592 & -8.0755 & 1.0438 \\
ITIP $<0$ & 3,145 & -0.0081 & 0.0172 & -0.1766 & 0 \\
ITIPSB $<0$ & 3,145 & -0.0032 & 0.0050 & -0.0230 & 0 \\
ITIP $>0$ & 3,145 & 0.0211 & 0.0298 & 0 & 0.1722 \\
ITIPSB $>0$ & 3,145 & 0.0043 & 0.0053 & 0 & 0.0222 \\
SIZE & 3,145 & 6.8930 & 1.3556 & 3.7446 & 10.754 \\
INPL & 3,145 & 0.0480 & 0.0468 & 0.0008 & 0.4487 \\
lodep & 3,145 & 1.2601 & 1.6074 & 0.0202 & 25 \\
\hline \hline
\end{tabular}

Summary statistics of the variable included in the estimation of equation (6). 
Table 2. Pairwise Correlation Matrix

\begin{tabular}{|c|c|c|c|c|c|c|c|c|c|c|c|c|c|c|}
\hline & 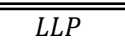 & oprofit & equity & loangr & 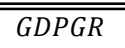 & $\overline{~ U N E M P}$ & roae & $\overline{I T I P}<0$ & $\overline{I T I P S B}<0$ & $\overline{I T I P}>0$ & $\overline{\overline{I T I P S B}>0}$ & SIZE & 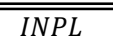 & lodep \\
\hline$L L P$ & 1 & & & & & & & & & & & & & \\
\hline oprofit & $0.0595^{*}$ & 1 & & & & & & & & & & & & \\
\hline equity & $-0.0334 *$ & $0.2596^{*}$ & 1 & & & & & & & & & & & \\
\hline loangr & $-0.0602 *$ & $0.1025^{*}$ & $0.0386^{*}$ & 1 & & & & & & & & & & \\
\hline$G D P G R$ & $-0.1069^{*}$ & $0.1081^{*}$ & 0.0195 & $0.1546^{*}$ & 1 & & & & & & & & & \\
\hline UNEMP & $0.0948^{*}$ & $-0.0423 *$ & -0.0137 & $-0.0474 *$ & $-0.1459 *$ & 1 & & & & & & & & \\
\hline roae & $-0.2871^{*}$ & $0.2305^{*}$ & 0.00870 & $0.0720^{*}$ & $0.2036^{*}$ & $-0.1099^{*}$ & 1 & & & & & & & \\
\hline$I T I P<0$ & $-0.0887 *$ & 0.0206 & $-0.0296^{*}$ & 0.0162 & $0.0920 *$ & -0.00430 & $0.0418^{*}$ & 1 & & & & & & \\
\hline$I T I P S B<0$ & $0.0657^{*}$ & -0.0233 & $-0.0829 *$ & $-0.0907^{*}$ & $-0.2349 *$ & $0.1067^{*}$ & $-0.0671^{*}$ & $-0.2515^{*}$ & 1 & & & & & \\
\hline$I T I P>0$ & $-0.0483 *$ & $-0.0469 *$ & $0.0626^{*}$ & 0.00280 & $0.0458^{*}$ & -0.0244 & $0.0365^{*}$ & $0.3403^{*}$ & $-0.2638^{*}$ & 1 & & & & \\
\hline $\operatorname{ITIPSB}>0$ & 0.0173 & $-0.0483 *$ & $-0.0613^{*}$ & $-0.1097^{*}$ & $-0.1479 *$ & $0.1900^{*}$ & $-0.0645^{*}$ & $-0.1136^{*}$ & $0.5356^{*}$ & $0.1063^{*}$ & 1 & & & \\
\hline SIZE & $-0.0709 *$ & $-0.0542 *$ & $-0.3063^{*}$ & 0.00400 & $-0.0465^{*}$ & -0.0225 & $0.0750^{*}$ & -0.00400 & $0.3150^{*}$ & $0.1089^{*}$ & $0.3376^{*}$ & 1 & & \\
\hline$I N P L$ & $0.1153^{*}$ & $-0.0306^{*}$ & $-0.0391 *$ & $-0.1046^{*}$ & $-0.3237^{*}$ & $0.5767^{*}$ & $-0.1854^{*}$ & $-0.0525^{*}$ & $0.2394 *$ & -0.0230 & $0.3082 *$ & -0.0109 & 1 & \\
\hline lodep & -0.00220 & 0.0272 & $0.1843^{*}$ & -0.0163 & $-0.0502 *$ & $0.0375^{*}$ & $-0.0447 *$ & $-0.2843 *$ & 0.0246 & -0.00340 & 0.00820 & $-0.0512 *$ & $0.0303^{*}$ & 1 \\
\hline
\end{tabular}

Pearson's correlation coefficients

* Statistically significant at $10 \%$ 
Table 3. TIP and TIP scale biased results

\begin{tabular}{|c|c|c|c|c|c|}
\hline $\begin{array}{l}\text { Panel A } \\
\text { TIP }\end{array}$ & & & $\begin{array}{c}\text { Frequency } \\
\text { (significant } \\
\text { TIP) }\end{array}$ & $\begin{array}{c}\text { Average TIP } \\
(\%)\end{array}$ & $\begin{array}{c}\text { Total } \\
\text { observatio } \\
\text { ns } \\
\end{array}$ \\
\hline $\begin{array}{l}\text { Quintile } \\
\text { Smallest }\end{array}$ & $\overline{c 1}$ & - & 71 & 11.29 & 629 \\
\hline $\begin{array}{l}\text { Quintile } \\
\text { Small }\end{array}$ & 2 & - & 324 & 51.51 & 629 \\
\hline $\begin{array}{l}\text { Quintile } \\
\text { Medium }\end{array}$ & 3 & - & 414 & 65.82 & 629 \\
\hline $\begin{array}{l}\text { Quintile } \\
\text { Large }\end{array}$ & 4 & - & 329 & 52.31 & 629 \\
\hline $\begin{array}{l}\text { Quintile } \\
\text { Largest }\end{array}$ & 5 & - & 73 & 11.61 & 629 \\
\hline Overall & & & 1,211 & 38.51 & 3,145 \\
\hline $\begin{array}{l}\text { Panel B } \\
\text { TIPSB }\end{array}$ & & & $\begin{array}{c}\text { Frequency } \\
\text { (significant } \\
\text { TIPSB) } \\
\end{array}$ & $\begin{array}{c}\text { Average TIPSB } \\
(\%)\end{array}$ & $\begin{array}{c}\text { Total } \\
\text { observatio } \\
\text { ns } \\
\end{array}$ \\
\hline $\begin{array}{l}\text { Quintile } \\
\text { Smallest }\end{array}$ & 1 & - & 368 & 58.51 & 629 \\
\hline $\begin{array}{l}\text { Quintile } \\
\text { Small }\end{array}$ & 2 & - & 358 & 56.92 & 629 \\
\hline $\begin{array}{l}\text { Quintile } \\
\text { Medium }\end{array}$ & 3 & - & 313 & 49.76 & 629 \\
\hline $\begin{array}{l}\text { Quintile } \\
\text { Large }\end{array}$ & 4 & - & 218 & 34.66 & 629 \\
\hline
\end{tabular}


Table 4. Results of Loan Loss Provisioning Identification

\begin{tabular}{|c|c|c|c|c|c|}
\hline & \multicolumn{2}{|c|}{ Dynamic Models } & \multicolumn{3}{|c|}{ Static Models } \\
\hline & SGMM & $\begin{array}{l}\text { Pooled OLS } \\
\text { with lag }\end{array}$ & Pooled OLS & VIF & Fixed Effects \\
\hline$L L P(t-1)$ & $\begin{array}{l}0.2801^{* * *} \\
(0.0802)\end{array}$ & $\begin{array}{l}0.5880^{* * *} \\
(0.149)\end{array}$ & & & \\
\hline oprofit & $\begin{array}{l}0.4780^{* * *} \\
(0.155)\end{array}$ & $\begin{array}{l}0.2310^{* *} \\
(0.107)\end{array}$ & $\begin{array}{l}0.2930^{* *} \\
(0.133)\end{array}$ & 1.16 & $\begin{array}{l}0.2880^{* * *} \\
(0.110)\end{array}$ \\
\hline equity & $\begin{array}{l}-0.0404 \\
(0.0284)\end{array}$ & $\begin{array}{l}-0.0203 \\
(0.0148)\end{array}$ & $\begin{array}{l}-0.0229 \\
(0.0184)\end{array}$ & 1.21 & $\begin{array}{l}-0.136^{* *} \\
(0.0614)\end{array}$ \\
\hline loangr & $\begin{array}{l}-0.0016 \\
(0.0049)\end{array}$ & $\begin{array}{l}-0.0003 \\
(0.0019)\end{array}$ & $\begin{array}{l}-0.0029 \\
(0.0023)\end{array}$ & 1.06 & $\begin{array}{l}-0.0025 \\
(0.0019)\end{array}$ \\
\hline$G D P G R$ & $\begin{array}{l}-0.0477^{* * *} \\
(0.0142)\end{array}$ & $\begin{array}{l}-0.0360^{* * *} \\
(0.0135)\end{array}$ & $\begin{array}{l}-0.0292^{* *} \\
(0.0146)\end{array}$ & 1.43 & $\begin{array}{l}-0.0355^{* * *} \\
(0.0129)\end{array}$ \\
\hline$U N E M P$ & $\begin{array}{c}0.0544 \\
(0.0523)\end{array}$ & $\begin{array}{l}0.0320 \\
(0.0334)\end{array}$ & $\begin{array}{c}0.0642 \\
(0.0725)\end{array}$ & 1.56 & $\begin{array}{l}-0.0172 \\
(0.0482)\end{array}$ \\
\hline roae & $\begin{array}{l}-0.0351^{* * *} \\
(0.0072)\end{array}$ & $\begin{array}{l}-0.0356^{* * *} \\
(0.0059)\end{array}$ & $\begin{array}{l}-0.0444^{* * *} \\
(0.0069)\end{array}$ & 1.15 & $\begin{array}{l}-0.0434^{* * *} \\
(0.0074)\end{array}$ \\
\hline$I T I P<0$ & $\begin{array}{l}-0.0917^{* *} \\
(0.0369)\end{array}$ & $\begin{array}{l}-0.0599^{*} \\
(0.0340)\end{array}$ & $\begin{array}{l}-0.0713 \\
(0.0544)\end{array}$ & 1.32 & $\begin{array}{l}-0.0106 \\
(0.0393)\end{array}$ \\
\hline$I T I P S B<0$ & $\begin{array}{l}0.3170^{* *} \\
(0.144)\end{array}$ & $\begin{array}{l}0.2910^{* * *} \\
(0.100)\end{array}$ & $\begin{array}{l}0.417^{* * *} \\
(0.138)\end{array}$ & 2.31 & $\begin{array}{c}0.298 \\
(0.250)\end{array}$ \\
\hline$I T I P>0$ & $\begin{array}{c}0.0344 \\
(0.0352)\end{array}$ & $\begin{array}{l}0.00230 \\
(0.0144)\end{array}$ & $\begin{array}{c}0.0087 \\
(0.0158)\end{array}$ & 1.38 & $\begin{array}{l}-0.0263 \\
(0.0610)\end{array}$ \\
\hline$I T I P S B>0$ & $\begin{array}{l}-0.0682 \\
(0.117)\end{array}$ & $\begin{array}{l}-0.0583 \\
(0.0809)\end{array}$ & $\begin{array}{l}-0.0469 \\
(0.117)\end{array}$ & 2.15 & $\begin{array}{l}0.0013 \\
(0.172)\end{array}$ \\
\hline$S I Z E$ & $\begin{array}{l}-0.0020^{* * *} \\
(0.0007)\end{array}$ & $\begin{array}{l}-0.0009^{*} \\
(0.0004)\end{array}$ & $\begin{array}{l}-0.0022^{* * *} \\
(0.0003)\end{array}$ & 1.42 & $\begin{array}{l}-0.0033 \\
(0.0045)\end{array}$ \\
\hline$I N P L$ & $\begin{array}{c}0.0016 \\
(0.0198)\end{array}$ & $\begin{array}{l}-0.0138 \\
(0.0148)\end{array}$ & $\begin{array}{c}0.0073 \\
(0.0271)\end{array}$ & 2.03 & $\begin{array}{c}0.0500^{* *} \\
(0.0197)\end{array}$ \\
\hline lodep & $\begin{array}{l}-0.0001 \\
(0.0003)\end{array}$ & $\begin{array}{l}-0.0002 \\
(0.0002)\end{array}$ & $\begin{array}{l}-0.0004 \\
(0.0005)\end{array}$ & 1.15 & $\begin{array}{l}-0.0017 \\
(0.0017)\end{array}$ \\
\hline crisis & $\begin{array}{c}0.0012 \\
(0.0008)\end{array}$ & $\begin{array}{l}-0.0002 \\
(0.0008)\end{array}$ & $\begin{array}{c}0.0013 \\
(0.0011)\end{array}$ & 1.56 & $\begin{array}{c}0.0006 \\
(0.0008)\end{array}$ \\
\hline$E U 15$ & $\begin{array}{l}-0.0024^{*} \\
(0.0013)\end{array}$ & $\begin{array}{l}-0.0025^{* * *} \\
(0.0010)\end{array}$ & $\begin{array}{l}-0.0035^{* * *} \\
(0.0013)\end{array}$ & 1.29 & $\begin{array}{l}-0.0222 \\
(0.0193)\end{array}$ \\
\hline listed & $\begin{array}{c}0.0002 \\
(0.0010)\end{array}$ & $\begin{array}{l}0.0009 \\
(0.0007)\end{array}$ & $\begin{array}{l}0.0014 \\
(0.0009)\end{array}$ & 1.05 & $\begin{array}{c}0.0433^{*} \\
(0.0231)\end{array}$ \\
\hline constant & $\begin{array}{l}0.0179^{* * *} \\
(0.0069)\end{array}$ & $\begin{array}{l}0.0123^{* *} \\
(0.0057)\end{array}$ & $\begin{array}{l}0.0242^{* * *} \\
(0.0072)\end{array}$ & & $\begin{array}{l}0.0480 \\
(0.0393)\end{array}$ \\
\hline$N$ & 3145 & 3145 & 3195 & & 3195 \\
\hline$R^{2}$ & & 0.622 & 0.187 & & 0.218 \\
\hline Robust Hausman test (p-value) & & & & & 0.000 \\
\hline AR(1) test (p-value) & 0.000 & & & & \\
\hline AR(2) test ( $p$-value) & 0.957 & & & & \\
\hline Lags & $2-4$ & & & & \\
\hline IV count (groups) & $442(450)$ & & & & \\
\hline $\begin{array}{l}\text { Hansen test of overidentification } \\
\text { (p-value) }\end{array}$ & 0.516 & & & & \\
\hline $\begin{array}{l}\text { Underidentification test for } \\
\text { differenced equation }\end{array}$ & 0.0078 & & & & \\
\hline $\begin{array}{l}\text { Underidentification test for levels } \\
\text { equation }\end{array}$ & 0.0220 & & & & \\
\hline
\end{tabular}

equation only the key diagnostics here. A detailed description of the additional statistics is presented in Supplementary Appendix D. $A R(1)$ and $A R(2)$ are tests for first and second order serial correlation, under the null hypothesis of no serial correlation. The 'lags' show the number of lags used in the GMM model for bank specific variables. The Hansen test of overidentification is under the null that all instruments are valid. 
Table 5. Additional Analyses

\begin{tabular}{|c|c|c|c|}
\hline & $\begin{array}{l}\text { Model } 1 \\
\text { Without Tech Change }\end{array}$ & $\begin{array}{l}\text { Model } 2 \\
\text { Post Crisis } \\
\text { Income smoothing }\end{array}$ & $\begin{array}{l}\text { Model } 3 \\
\text { Non-Linear } \\
\text { Income Smoothing }\end{array}$ \\
\hline$L L P(t-1)$ & $\begin{array}{c}0.2550^{* * *} \\
(0.0776)\end{array}$ & $\begin{array}{c}0.2890^{* * *} \\
(0.0774)\end{array}$ & $\begin{array}{c}0.2670^{* * *} \\
(0.0798)\end{array}$ \\
\hline oprofit & $\begin{array}{l}0.6390^{* * *} \\
(0.1650)\end{array}$ & $\begin{array}{l}0.5080^{* * *} \\
(0.1640)\end{array}$ & \\
\hline crisis $\times$ oprofit & & $\begin{array}{r}0.0133 \\
(0.147)\end{array}$ & \\
\hline doprofit & & & $\begin{array}{l}0.3006^{* * *} \\
(0.0690)\end{array}$ \\
\hline equity & $\begin{array}{l}-0.0513 \\
(0.0343)\end{array}$ & $\begin{array}{l}-0.0456 \\
(0.0297)\end{array}$ & $\begin{array}{l}-0.0371 \\
(0.0268)\end{array}$ \\
\hline loangr & $\begin{array}{l}-0.0015 \\
(0.0050)\end{array}$ & $\begin{array}{l}-0.0014 \\
(0.0052)\end{array}$ & $\begin{array}{c}0.0015 \\
(0.0052)\end{array}$ \\
\hline$G D P G R$ & $\begin{array}{l}-0.0529^{* * *} \\
(0.0162)\end{array}$ & $\begin{array}{l}-0.0415^{* *} \\
(0.0183)\end{array}$ & $\begin{array}{l}-0.0390^{* * *} \\
(0.0132)\end{array}$ \\
\hline$U N E M P$ & $\begin{array}{c}0.0500 \\
(0.0559)\end{array}$ & $\begin{array}{c}0.0511 \\
(0.0536)\end{array}$ & $\begin{array}{r}0.0517 \\
(0.054)\end{array}$ \\
\hline roae & $\begin{array}{l}-0.0395^{* * *} \\
(0.0087)\end{array}$ & $\begin{array}{l}-0.0357^{* * *} \\
(0.0073)\end{array}$ & $\begin{array}{l}-0.0344^{* * *} \\
(0.0068)\end{array}$ \\
\hline$I T I P<0$ & & $\begin{array}{l}-0.0831^{* *} \\
(0.0332)\end{array}$ & $\begin{array}{l}-0.0855^{* *} \\
(0.0383)\end{array}$ \\
\hline$I T I P S B<0$ & & $\begin{array}{c}0.3170^{* *} \\
(0.1490)\end{array}$ & $\begin{array}{c}0.3820^{* *} \\
(0.1570)\end{array}$ \\
\hline$I T I P>0$ & & $\begin{array}{c}0.0328 \\
(0.0376)\end{array}$ & $\begin{array}{c}0.0427 \\
(0.0351)\end{array}$ \\
\hline$I T I P S B>0$ & & $\begin{array}{c}-0.0639 \\
(0.108)\end{array}$ & $\begin{array}{l}-0.156 \\
(0.123)\end{array}$ \\
\hline$S I Z E$ & $\begin{array}{c}0.0005 \\
(0.0014)\end{array}$ & $\begin{array}{l}-0.0021^{* * *} \\
(0.0008)\end{array}$ & $\begin{array}{l}-0.0018^{* *} \\
(0.0007)\end{array}$ \\
\hline$I N P L$ & $\begin{array}{c}0.0087 \\
(0.0211)\end{array}$ & $\begin{array}{c}0.0089 \\
(0.0238)\end{array}$ & $\begin{array}{c}0.0067 \\
(0.0196)\end{array}$ \\
\hline lodep & $\begin{array}{c}0.0003 \\
(0.0004)\end{array}$ & $\begin{array}{l}-0.0001 \\
(0.0004)\end{array}$ & $\begin{array}{c}0.0001 \\
(0.0003)\end{array}$ \\
\hline crisis & $\begin{array}{c}0.0023^{* *} \\
(0.0011)\end{array}$ & $\begin{array}{c}0.0012 \\
(0.0024)\end{array}$ & $\begin{array}{c}0.0005 \\
(0.0008)\end{array}$ \\
\hline$E U 15$ & $\begin{array}{l}-0.0027^{* *} \\
(0.0013)\end{array}$ & $\begin{array}{l}-0.0005 \\
(0.0028)\end{array}$ & $\begin{array}{l}-0.0027^{* *} \\
(0.0012)\end{array}$ \\
\hline listed & $\begin{array}{l}-0.0008 \\
(0.0013)\end{array}$ & $\begin{array}{l}-0.0031 \\
(0.0035)\end{array}$ & $\begin{array}{c}0.0007 \\
(0.0009)\end{array}$ \\
\hline constant & $\begin{array}{l}-0.0004 \\
(0.0120)\end{array}$ & $\begin{array}{c}0.0168^{* * *} \\
(0.0063)\end{array}$ & $\begin{array}{l}0.0212^{* * *} \\
(0.0072)\end{array}$ \\
\hline$N$ & 3145 & 3145 & 3145 \\
\hline AR(1) test (p-value) & 0.000 & 0.000 & 0.000 \\
\hline AR(2) test (p-value) & 0.919 & 0.945 & 0.828 \\
\hline Lags & $2-6$ & $2-4$ & $2-4$ \\
\hline IV count (groups) & $390(450)$ & $442(450)$ & $443(450)$ \\
\hline Hansen (p-value) & 0.290 & 0.470 & 0.511 \\
\hline Year Effects & Insignificant & Insignificant & Insignificant \\
\hline
\end{tabular}

${ }^{*} p<0.10,{ }^{* *} p<0.05,{ }^{* * *} p<0.01$. Windmeijer (2005) robust standard errors reported. $A R(1)$ and $A R(2)$ are tests for first and second order serial correlation, under the null hypothesis of no serial correlation. The 'lags' show the number of lags used in the GMM model for bank specific variables. Our results hold under different lag choices. The Hansen test of overidentification is under the null that all instruments are valid. 
Figure 1. Distributions of Technological Change and Scale Biased Technological Change: pre and post-crisis - Vertical lines represent the median. Values less than zero indicate technological progress

Panel A: Technological Innovative Progress (TIP)

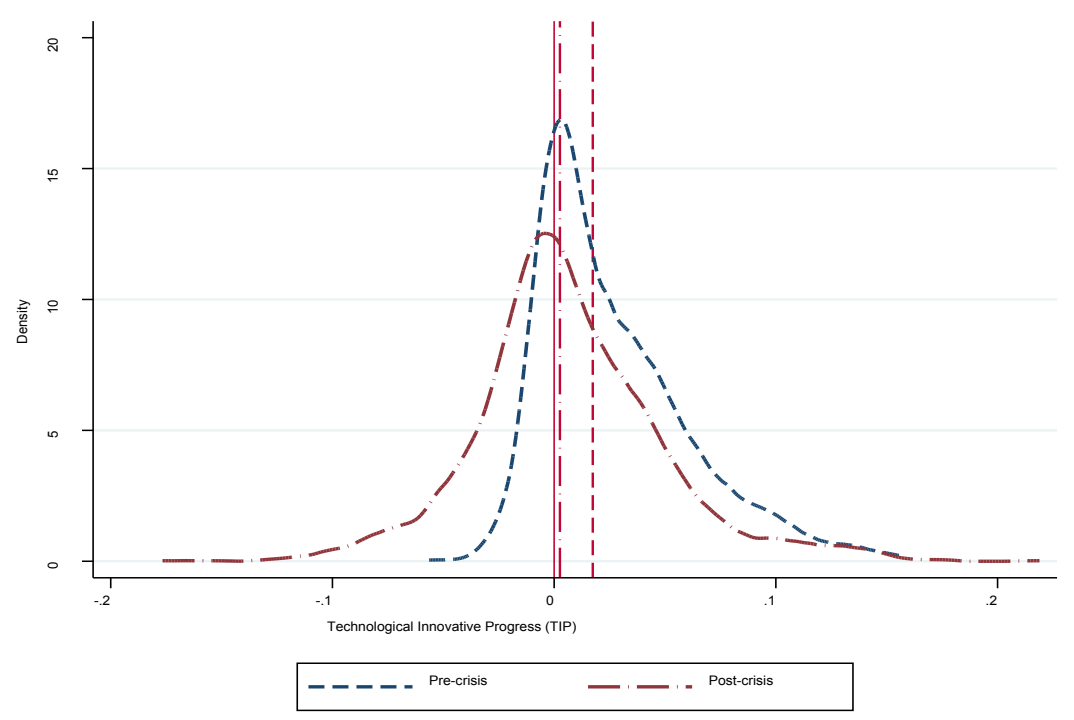

Panel B: Technological Innovative Progress Scale Biased (TIPSB)

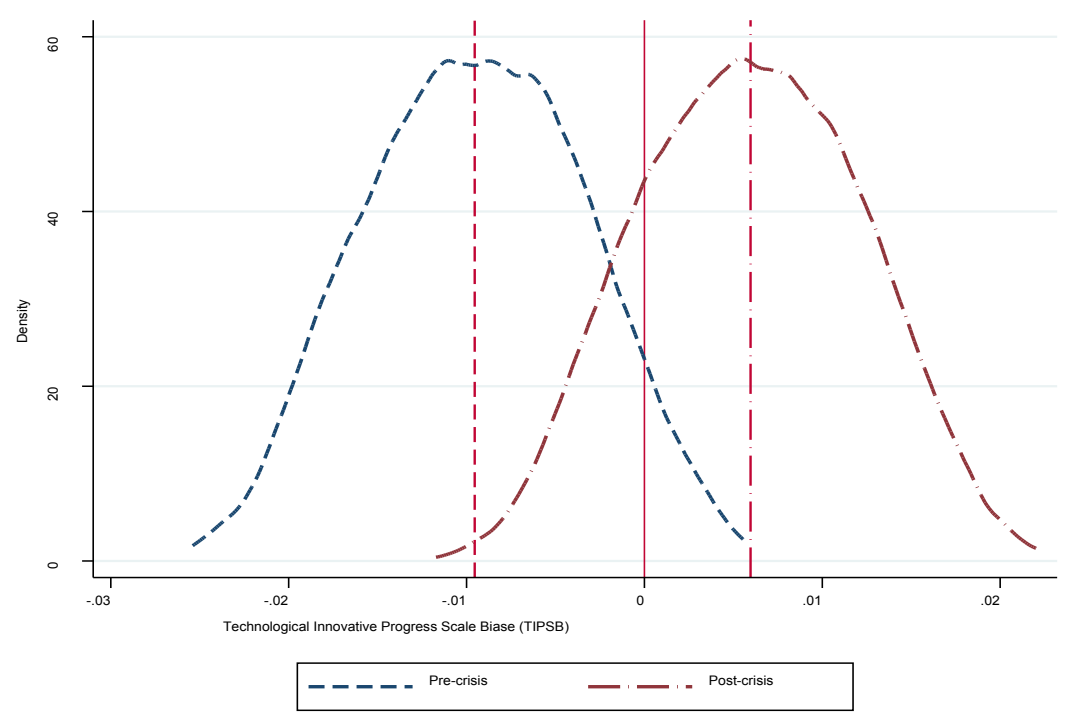


Figure 2. Distributions of banks exhibiting technological progress and scale biased technological progress - Vertical lines represent the median

Panel A: Technological Innovative Progress (TIP)

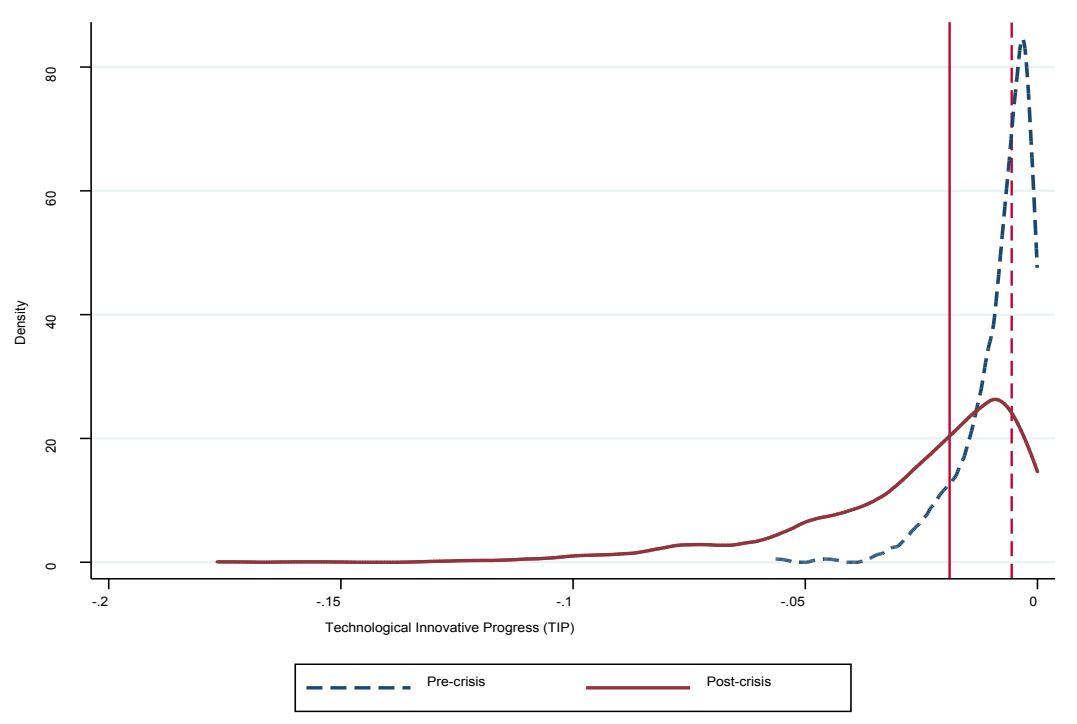

Panel B. Technological Innovative Progress Scale Biased (TIPSB)

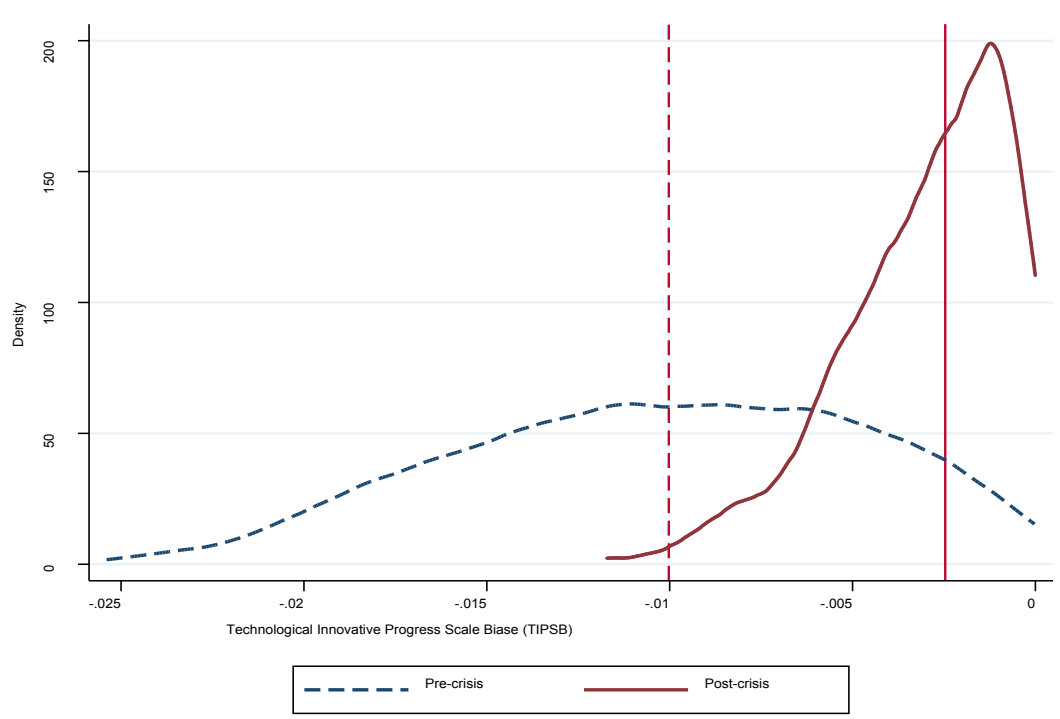




\section{Online Supplementary Appendix for}

\section{"European bank loan loss provisioning and technological innovative progress"}

The aim of this appendix is to provide supplementary information concerning the sample used in the study, the research design and implementation, robustness analysis and supporting information for Table 4. This appendix is structured as follows: Appendix A presents the Stochastic Frontier cost function utilised in the estimation of Technological Innovative Progress. Appendix B provides details concerning the sample used in the study. Appendix C offers additional System Generalised Method of Moments (SGMM) diagnostics and robustness checks, and finally, Appendix D provides information concerning Table 4. 


\section{Appendix A: Stochastic Frontier Analysis Cost Function Estimation}

This section provides details with respect to the estimation of two Technological Innovative Progress proxies, TIP and TIPSB. To obtain estimates of ITIP(SB) we use a standard cost frontier which assumes banks minimize costs subject to exogenously driven input prices, quantities of outputs/netputs, macro-economic conditions, their own managerial inefficiency, and a random error. This cost minimization behavior can be modelled via a cost function that relates variable costs to exogenous factors, given input prices, (assuming banks choose an input mix to minimize costs), equation (A.1). We define our translog as an extension of Hunter \& Timme (1991) and Drake \& Simper (2002), including a polynomial in time $(T)$ to capture technological change (time subscript dropped to reduce notation), equation (A.1),

$\ln \left(C_{i}\right)$

$$
\begin{aligned}
& =\operatorname{con}+\sum_{K=1}^{3} \alpha_{i} \ln y_{k i t}+\frac{1}{2} \\
& \sum_{k=1}^{3} \sum_{n=1}^{3} \sigma_{k n} \ln y_{k i t} \ln y_{n i t}+\sum_{m=1}^{3} \beta_{m} \ln w_{m i t}+\frac{1}{2} \sum_{m=1}^{3} \sum_{l=1}^{3} \gamma_{m l} \ln w_{m i t} \ln w_{l i t}
\end{aligned}
$$

$+\frac{1}{2} \sum_{k=1}^{3} \sum_{m=1}^{3} \delta_{k m} \ln y_{k i t} l n w_{m i t}+\tau_{1} \ln e q_{i i}+\frac{1}{2} \tau_{2} \ln e q_{i i}^{2}+\tau_{i T} \ln e q_{i} T+\frac{1}{2} \tau_{i T T} \ln e q_{i} T^{2}$

$+\eta_{t} T+\frac{1}{2} \eta_{T T} T^{2}+\sum_{k=1}^{3} \eta_{T k} T \ln y_{k i t}+\sum_{m=1}^{3} \mu_{T m} T \ln w_{m i t}+\frac{1}{2} \sum_{k=1}^{3} \eta_{t t k} T^{2} \ln y_{k i t}+\frac{1}{2} \sum_{m=1}^{3} \eta_{t t m} T^{2}$

$+\frac{1}{2} \sum_{k=1}^{3} \sum_{n=1}^{3} \eta_{T k n} \operatorname{Tlny}_{k i t} \operatorname{lny}_{n i t}+\theta_{1} E U 15++u_{i}$

Where, $C_{i t}$ is total costs, $w_{i t}$ are input prices for staff expenses, loanable funds, and physical capital, $y_{i t}$ are bank outputs (loans, other income deriving assets and net off balance sheet income), equity $e q_{i t}$ a fixed netput controlling for managerial risk appetite, funding costs and also scale bias when comparing banks of various sizes (see also, Staikouras et al. 2008 and Kalyvas and Mamatzakis, 2014), EU15 is a dummy variable to account for country effects (defined as in the list of countries in Table A.1), $u$ is the stochastic error term. Finally, the usual symmetry and linear homogeneity in input prices restrictions are imposed in estimation of equation (A.1). 


\section{Appendix B: The Sample}

In this appendix we provide additional details concerning the sample of banks used in the analysis. Table B.1 provides frequency distributions of the number of banks per country for the SGMM sample (after taking lags). It can be noted that the largest number of banks in our sample are from Germany (18.31\%), France (15.61\%) and Italy (9.35\%). Table B.2 provides the total number of bank year observations comprised in the final SGMM sample per country and year. The majority of countries show a stable number of banks across each year (for example, Germany having between 44 to 56 bank year observations). Ireland is excluded from the sample as we found considerable varying data problems. Finally, Table B.3 reports the descriptive statistics on the total assets of the five quintiles for the sample used. Total assets range between $€ 42$ million to $€ 46,820$ million, with a mean of $€ 2,504$ million and a standard deviation of $€ 4,376$ million.

INSERT TABLES B.1, B.2 AND B.3

\section{Appendix C: Additional Analysis of Empirical Results}

This section provides additional analysis of the main empirical results. This appendix is structured as follows: Section 1 presents an additional discussion on the distributions of TIP(SB), Section 2 presents diagnostics on the validity of the instruments used in the SGMM Model 1 (Equation 6), Section 3 presents additional System GMM regressions and robustness checks, and finally, Section 4 presents details supplementary information for Table 4.

\section{C.1 Technological Innovative Progress (TIP) Results}

This section offers additional analysis of the distributions of TIP(SB) for each asset size cluster as identified in Table A.3, appendix A. Figure C.1 presents the distribution of TIP for each asset class where we see that the results are overall symmetrical - minimum and maximum equal to -0.1766 and 0.1722 respectively. However, the smallest and largest asset sized quintiles for banks are predominately skewed towards decreasing TIP in relation to the remaining quintiles. The latter graphical relationship can also be seen in Figure C.2 where in terms of TIPSB, where the large and largest banks (quintiles 4 and 5 respectively) are also skewed to the right. This implies any efficient size effect due to TIP is predominately dominated by the medium and smaller banks - ceteris paribus, the larger banks have smaller scale technological efficiencies relative to smaller banks. 


\section{INSERT FIGURES C. 1 AND C.2}

\section{C.2 System GMM diagnostics}

To further investigate the validity of the instruments used in the SGMM Model 1, we follow Wintoki, Linck \& Netter (2012) and split Equation (4) is its two constituent parts and we assess the relevance of the instruments used for each equation separately. More specifically we approximate the levels and differenced equation estimated in the SGMM and we assess the lagged levels instruments used in the difference equation (equation [C.1]) and the lagged differences used as instruments in the levels equation (equation [C.2]). We perform these tests by estimating two separate two-stage least squares (2SLS) regressions.

$$
\begin{array}{cc}
\Delta \mathrm{LLP}_{i t}=\sum_{j=1}^{J} \alpha_{j} \Delta L L P_{i t-j}+\beta \boldsymbol{X}_{i t}+\Delta \varepsilon_{i t} & \text { Instruments: } L L P_{i t-2}, \boldsymbol{X}_{i t-2} \\
\mathrm{LLP}_{i t}=\sum_{j=1}^{J} \alpha_{j} L L P_{i t-j}+\beta \boldsymbol{X}_{i t}+\varepsilon_{i t} & \text { Instruments: } \Delta L L P_{i t-1}, \\
\Delta \boldsymbol{X}_{i t-1}
\end{array}
$$

Table C.1 reports the Sanderson-Windmeijer (SW) first-stage chi-square test of underidentification of individual endogenous regressors. Panels A and B report the first stage underidentification statistics form the 2SLS estimation of equations (C.1) and (C.2) respectively. We report results for the equation in differences (levels) for the bank specific variables entering the SGMM estimation in the instrumental variables matrix in a diagonal form as in Arellano and Bond (1991). In all first stage regressions, we reject the null hypotheses of underidentification for the individual bank specific variables. We also reject the joint underidentification hypothesis (Anderson statistic LM statistic), for both the equation in difference and in levels with p-values of 0.0078 and 0.0220 respectively, indicating that the both models are identified. Overall, the results suggest that the instruments chosen in the SGMM are relevant. It should be noted that these tests serve as an indication for the quality of the instruments used in the SGMM, as consistency of the SGMM estimates implies the joint estimation of the differenced and levels equations (that is, equations C.1 and C.2).

\section{INSERT TABLE C.1}




\section{C.3 Robustness checks}

In this section we present additional robustness checks to further analyse the consistency of the estimated SGMM model against potentially influential observations. We estimate equation (6) on a sample resulting from trimming a fraction of the observations when excluding influential data points. More specifically, we consider three approaches. In the first approach (R1), we remove outliers identified as the largest prediction errors from equation (6). Specifically, we estimate equation (6) again, after excluding the observations corresponding to the largest $1 \%$ of squared residuals. The second approach (R2), focuses on removing influential observations corresponding to equity capital (equity) equal to or larger than the 99th empirical percentile ${ }^{1}$. Finally, we estimate equation (6) omitting to control for moral hazard (R3), thus excluding equity from the model. Table C.2 presents the results from the additional panel data SGMM regression. The key TIP proxies, $\operatorname{ITIP}(S B)<0$, retain their sign, magnitude and significance under all additional regressions $(\mathrm{R} 1, \mathrm{R} 2 \mathrm{R} 3)$. Only ITIP $>0$ becomes significant under R2, however, maintaining its positive sign. When we remove the top $1 \%$ of the unconditional equity distribution, we now find tentative evidence in favour of the moral hazard hypothesis as equity now becomes significant at $10 \%$. Similarly, the estimated coefficient of the crisis dummy becomes significant at 10\%, keeping its magnitude and sign. Finally, results hold for the remaining control variables.

\section{INSERT TABLE C.2}

\section{Appendix D: Description of Table 4}

In this section we provide a detailed description of Table 4. More specifically, Section D.1 presents details for the Fixed Effects (FE) regression, Section D.2 discusses the Robust Hausman test, Section D.3 presents details on the SGMM diagnostics and Section D.4 presents further modelling choices.

\footnotetext{
${ }^{1}$ We undertake this robustness test on equity as our sample includes a potential outlier who had an equity ratio equal to $0.018,0.041$ and 0.046 , for 2003, 2004, 2005 respectively which then increases to over 0.8 in 2006, 2007 and 2008 due to a large capital injection. As mentioned above we find little to no effect in the robustness table and so acting conservative let the bank remain in the sample.
} 


\section{D.1 Fixed Effects Estimation}

For comparability with the Pooled OLS and the SGMM regressions, we use the Fixed Effect Filter (FEF) estimator proposed by Pesaran \& Zhou (2016) to obtain the coefficients of the time invariant EU15 and listed dummies that are omitted from the Fixed Effects (FE) model. The estimator is computed in two steps: In the first step, FE estimates are computed for the coefficients of the time-varying variables, and these estimates are used to filter out the timevarying effects. The residuals from the first stage panel regression are then averaged over time and used as a dependent variable in a cross-section ordinary least squares (OLS) regression that includes an intercept and the vector of the time-invariant regressors EU15 and listed dummies.

\section{D.2 Robust Hausman Test}

A test of fixed vs. random effects can also be seen as a test of overidentifying restrictions where the random effects estimator can be seen as using the additional restrictions that the regressors are uncorrelated with the group specific error term. To test these restrictions we follow Arellano (1993) and Wooldridge (2001) and we use the artificial regression where an augmented random effects equation is re-estimated and additional variables consisting of the original regressors transformed into deviations-from-mean form are included. The advantage of this test of the traditional Hausman test is that it can be robust to heteroskedasticity. We reject the null hypothesis of random-effects in favour of the alternative hypothesis of fixedeffect at the $1 \%$ level.

\section{D.3 SGMM Diagnostics}

$\mathrm{AR}(1)$ and $\mathrm{AR}(2)$ are tests for first-order and second-order serial correlation in the firstdifferenced residuals, under the null hypothesis of no serial correlation. The 'lags' show the number of lags used in the GMM model for bank specific variables. Our results hold under different lag choices. The Hansen test of over-identification is under the null that all instruments are valid. Under-identification test is the Kleibergen-Paap rk LM stat (p-value reported) of whether the equation is identified, i.e., that the excluded instruments are "relevant", meaning correlated with the endogenous regressors. The null hypothesis is that the equation is under-identified and a rejection of the null indicates that the matrix is full column rank, i.e., the model is identified. This test is estimated following equations (C.1) and (C.2), Appendix C. 


\section{D.4 Further Modelling Choices}

Time dummies in preliminary analysis, where found to be jointly insignificant in all specifications and consequently they were not included in the analysis. Furthermore, in unreported results, we included country specific dummies in the SGMM. The results hold and remain consistent to the ones presented here. 
Table B.1 Frequency distributions of countries

\begin{tabular}{lccc}
\hline Country & Frequency & Percent (\%) & Cumulative. \\
Austria & 195 & 6.2 & 6.2 \\
Belgium & 76 & 2.42 & 8.62 \\
Bulgaria & 44 & 1.4 & 10.02 \\
Cyprus & 14 & 0.45 & 10.46 \\
Czech Republic & 54 & 1.72 & 12.18 \\
Germany & 576 & 18.31 & 30.49 \\
Denmark & 283 & 9 & 39.49 \\
Estonia & 22 & 0.7 & 40.19 \\
Spain & 51 & 1.62 & 41.81 \\
Finland & 17 & 0.54 & 42.35 \\
France & 491 & 15.61 & 57.97 \\
UK & 168 & 5.34 & 63.31 \\
Greece & 22 & 0.7 & 64.01 \\
Hungary & 32 & 1.02 & 65.02 \\
Italy & 294 & 9.35 & 74.37 \\
Lithuania & 80 & 2.54 & 76.92 \\
Luxembourg & 137 & 4.36 & 81.27 \\
Latvia & 125 & 3.97 & 85.25 \\
Malta & 18 & 0.57 & 85.82 \\
Netherlands & 24 & 0.76 & 86.58 \\
Poland & 84 & 2.67 & 89.25 \\
Portugal & 32 & 1.02 & 90.27 \\
Romania & 43 & 1.37 & 91.64 \\
Sweden & 101 & 3.21 & 94.85 \\
Slovenia & 100 & 3.18 & 98.03 \\
Slovakia & 62 & 1.97 & 100 \\
Total & 3,145 & 100 & \\
Number of banks & 450 & & \\
Number of countries & 26 & & \\
\hline
\end{tabular}

This table reports the frequency distribution of the sample used in the SGMM. In bold we highlight the EU15 countries. 
Table B.2. Number of banks in the sample (per year/country) [SGMM sample]

\begin{tabular}{|c|c|c|c|c|c|c|c|c|c|c|c|c|c|}
\hline Country & 2003 & 2004 & 2005 & 2006 & 2007 & 2008 & 2009 & 2010 & 2011 & 2012 & 2013 & 2014 & Panel \\
\hline Austria & 18 & 19 & 16 & 17 & 16 & 15 & 15 & 16 & 19 & 17 & 16 & 11 & 195 \\
\hline Belgium & 7 & 8 & 7 & 6 & 5 & 5 & 6 & 6 & 5 & 7 & 7 & 7 & 76 \\
\hline Bulgaria & 1 & 1 & 1 & 1 & 2 & 5 & 4 & 5 & 5 & 6 & 6 & 7 & 44 \\
\hline Cyprus & & & & & & & 1 & 2 & 3 & 2 & 3 & 3 & 14 \\
\hline Czech Republic & 1 & 1 & 2 & 4 & 5 & 5 & 5 & 6 & 7 & 6 & 6 & 6 & 54 \\
\hline Germany & 47 & 46 & 48 & 49 & 49 & 49 & 47 & 46 & 54 & 51 & 46 & 44 & 576 \\
\hline Denmark & 21 & 23 & 25 & 26 & 27 & 25 & 25 & 27 & 25 & 23 & 20 & 16 & 283 \\
\hline Estonia & 3 & 2 & 2 & 2 & 3 & 2 & 2 & 2 & 1 & 2 & 1 & & 22 \\
\hline Spain & & & & 1 & 7 & 8 & 8 & 7 & 5 & 6 & 4 & 5 & 51 \\
\hline Finland & & & 1 & 1 & 1 & 1 & 1 & 4 & 4 & 4 & & & 17 \\
\hline France & 35 & 35 & 35 & 36 & 39 & 43 & 43 & 41 & 43 & 46 & 49 & 46 & 491 \\
\hline UK & 11 & 11 & 12 & 13 & 14 & 12 & 17 & 17 & 15 & 16 & 16 & 14 & 168 \\
\hline Greece & & & & 1 & 2 & 3 & 4 & 3 & 3 & 3 & 2 & 1 & 22 \\
\hline Hungary & 1 & 2 & 2 & 2 & 2 & 2 & 3 & 4 & 4 & 4 & 3 & 3 & 32 \\
\hline Italy & & & & 3 & 34 & 35 & 35 & 34 & 39 & 40 & 40 & 34 & 294 \\
\hline Lithuania & 6 & 7 & 6 & 6 & 7 & 8 & 7 & 7 & 6 & 7 & 7 & 6 & 80 \\
\hline Luxembourg & 15 & 17 & 14 & 14 & 13 & 14 & 16 & 10 & 8 & 10 & 6 & & 137 \\
\hline Latvia & 9 & 9 & 9 & 10 & 10 & 11 & 11 & 12 & 11 & 13 & 12 & 8 & 125 \\
\hline Malta & & & 3 & 3 & 3 & 3 & 3 & 3 & & & & & 18 \\
\hline Netherlands & 2 & 2 & 1 & 1 & & & 1 & 3 & 3 & 3 & 4 & 4 & 24 \\
\hline Poland & 1 & 2 & 2 & 5 & 6 & 7 & 9 & 10 & 11 & 10 & 11 & 10 & 84 \\
\hline Portugal & & 1 & 1 & 2 & 3 & 4 & 4 & 5 & 4 & 3 & 3 & 2 & 32 \\
\hline Romania & & & 1 & 2 & 2 & 4 & 5 & 5 & 6 & 6 & 6 & 6 & 43 \\
\hline Sweden & 10 & 10 & 10 & 8 & 7 & 10 & 8 & 4 & 4 & 11 & 11 & 8 & 101 \\
\hline Slovenia & 5 & 5 & 5 & 6 & 10 & 10 & 11 & 9 & 9 & 11 & 11 & 8 & 100 \\
\hline Slovakia & 3 & 3 & 3 & 3 & 7 & 7 & 7 & 6 & 5 & 6 & 6 & 6 & 62 \\
\hline Total & 196 & 204 & 206 & 222 & 274 & 288 & 298 & 294 & 299 & 313 & 296 & 255 & 3,145 \\
\hline
\end{tabular}

This table reports the number of banks in the SGMM sample (per year/country). In bold we highlight the EU15 countries. 
Table B.3. Bank size classes: descriptive statistics

\begin{tabular}{lcccccc}
\hline \hline & Observations & Mean & Std Dev & Min & Median & Max \\
\hline \hline Quintile 1 - Smallest & 629 & 165.95 & 58.90 & 42.29 & 157.55 & 280.43 \\
Quintile 2 - Small & 629 & 464.51 & 113.03 & 280.48 & 460.09 & 669.78 \\
Quintile 3 - Medium & 629 & 953.87 & 180.25 & 670.46 & 941.71 & 1291.64 \\
Quintile 4 - Large & 629 & $2,021.18$ & 517.79 & $1,294.76$ & $1,958.56$ & $3,134.55$ \\
Quintile 5 - Largest & 629 & $8,916.67$ & $6,690.14$ & $3,137.99$ & $6,751.90$ & $4,6820.78$ \\
Overall & 3,145 & $2,504.44$ & $4,436.63$ & 42.29 & 941.71 & $4,6820.78$ \\
\hline \hline
\end{tabular}

Descriptive statistics on size for each size class (expressed in terms of total assets). Size values are expressed in millions of euro $(€)$. 
Figure C.1. Distributions of Technological Innovative Progress (TIP) per size classes

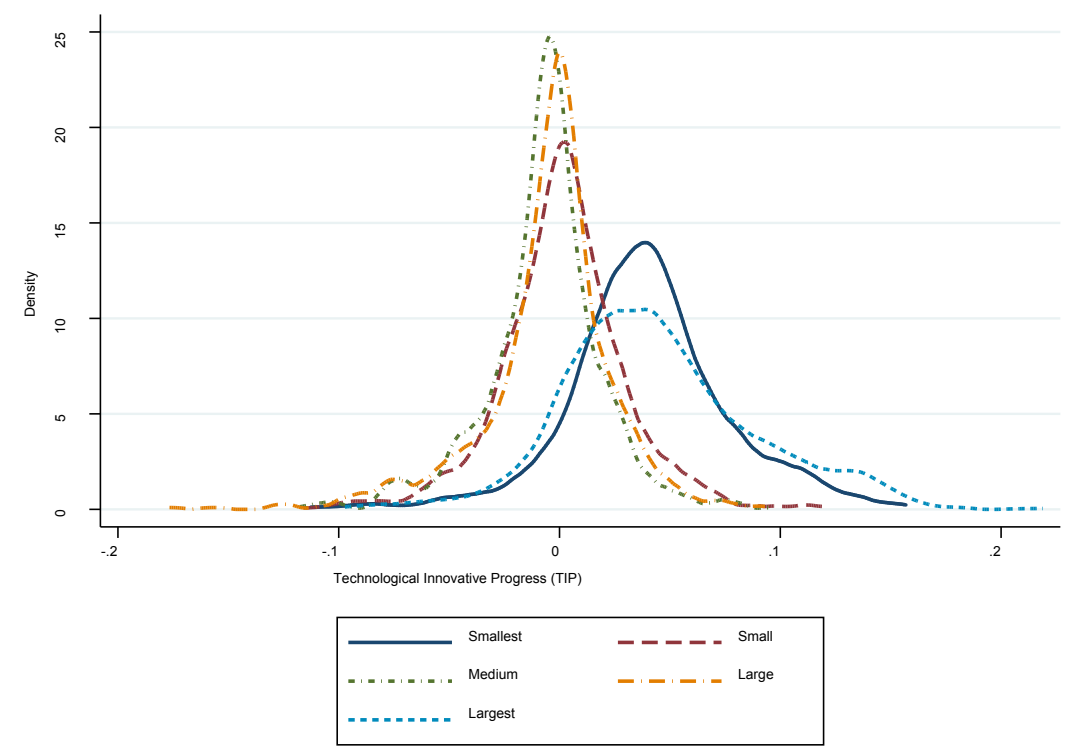

Figure C.2. Distributions of Technological Innovative Progress Scale Biased (TIPSB) per size classes.

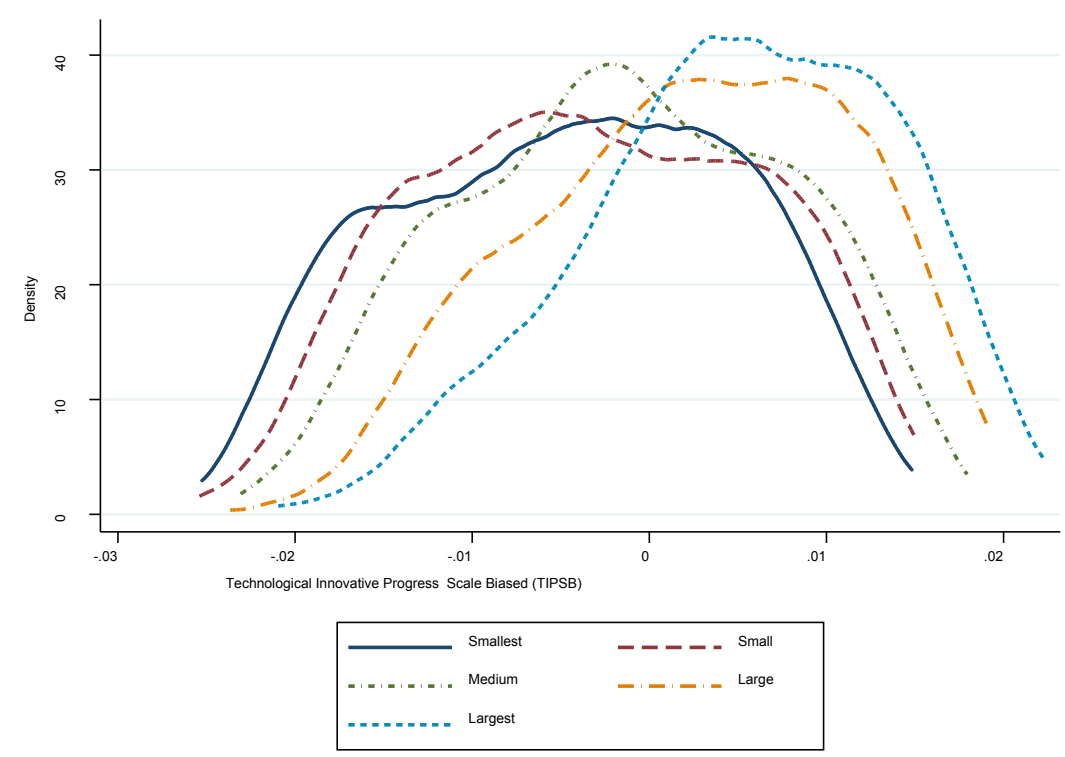


Table C.1. SGMM Diagnostics - Main Equation

\begin{tabular}{|c|c|c|}
\hline Joint Estimation & Panel $A$ & Panel B \\
\hline & "variables in differences & variables in levels \\
\hline & (Underid) - Sanderson- & (Underid) - Sanderson- \\
\hline & Windmeijer & Windmeijer \\
\hline $\operatorname{LLP}(t-1)$ & 0.0000 & 0.0000 \\
\hline oprofit & 0.0000 & 0.0000 \\
\hline equity & 0.0000 & 0.0000 \\
\hline loangr & 0.0000 & 0.0000 \\
\hline lodep & 0.0000 & 0.0000 \\
\hline roae & 0.0000 & 0.0000 \\
\hline$I T I P<0$ & 0.0000 & 0.0000 \\
\hline$I T I P S B<0$ & 0.0000 & 0.0000 \\
\hline$I T I P>0$ & 0.0000 & 0.0000 \\
\hline$I T I P S B>0$ & 0.0000 & 0.0000 \\
\hline SIZE & 0.0000 & 0.0000 \\
\hline $\begin{array}{l}\text { Under-identification test (Anderson LM } \\
\text { statistic) }\end{array}$ & $\chi_{305}^{2}(\mathrm{p}$-value $=0.0078)$ & $\chi_{107}^{2}(p-$ value $=0.0220)$ \\
\hline
\end{tabular}

The Sanderson-Windmeijer (SW) first-stage chi-squared is a test of under-identification of individual endogenous regressors. It is constructed by "partialling-out" linear projections of the remaining endogenous regressors, under the null that the particular endogenous regressor in question is unidentified. Under-identification test (Anderson statistic) is an LM test of whether the equation is identified, i.e., that the excluded instruments are "relevant", meaning correlated with the endogenous regressors. A rejection of the null hypothesis indicates that the model is identified. 
Table C.2. Robustness Checks - Outlier Identification

\begin{tabular}{|c|c|c|c|}
\hline & R1 & R2 & R3 \\
\hline \multirow[t]{2}{*}{$L L P(t-1)$} & $0.2834^{* * *}$ & $0.2995^{* * *}$ & $0.2769^{* * *}$ \\
\hline & $(0.0808)$ & $(0.0791)$ & $(0.0829)$ \\
\hline \multirow[t]{2}{*}{ oprofit } & $0.4578^{* * *}$ & $0.6151^{* * *}$ & $0.4266^{* * *}$ \\
\hline & $(0.1689)$ & $(0.1282)$ & $(0.1465)$ \\
\hline \multirow[t]{2}{*}{ equity } & -0.0371 & $-0.0600^{*}$ & \\
\hline & $(0.0255)$ & $(0.0338)$ & \\
\hline \multirow[t]{2}{*}{ loangr } & 0.0008 & -0.0051 & -0.0003 \\
\hline & $(0.0062)$ & $(0.0037)$ & $(0.0056)$ \\
\hline \multirow[t]{2}{*}{$G D P G R$} & $-0.0497^{* * *}$ & $-0.0452^{* * *}$ & $-0.0495^{* * *}$ \\
\hline & $(0.0143)$ & $(0.0118)$ & $(0.0134)$ \\
\hline \multirow{2}{*}{$U N E M P$} & 0.0503 & 0.0489 & 0.0542 \\
\hline & $(0.0532)$ & $(0.0451)$ & $(0.0529)$ \\
\hline \multirow[t]{2}{*}{ roae } & $-0.0362^{* * *}$ & $-0.0369^{* * *}$ & $-0.0336^{* * *}$ \\
\hline & $(0.0073)$ & $(0.0073)$ & $(0.0070)$ \\
\hline \multirow[t]{2}{*}{$I T I P<0$} & $-0.0854^{* *}$ & $-0.1022^{* * *}$ & $-0.0851^{* *}$ \\
\hline & $(0.0359)$ & $(0.0350)$ & $(0.0346)$ \\
\hline \multirow[t]{2}{*}{$I T I P S B<0$} & $0.3534^{* *}$ & $0.3421^{* *}$ & $0.2739^{*}$ \\
\hline & $(0.1433)$ & $(0.1379)$ & $(0.1522)$ \\
\hline \multirow{2}{*}{$I T I P>0$} & 0.0469 & $0.0653^{* *}$ & 0.0150 \\
\hline & $(0.0326)$ & $(0.0301)$ & $(0.0411)$ \\
\hline \multirow[t]{2}{*}{$I T I P S B>0$} & -0.0832 & -0.0596 & -0.0671 \\
\hline & $(0.1226)$ & $(0.1206)$ & $(0.1176)$ \\
\hline \multirow[t]{2}{*}{ SIZE } & $-0.0020^{* * *}$ & $-0.0027^{* * *}$ & $-0.0012^{*}$ \\
\hline & $(0.0006)$ & $(0.0009)$ & $(0.0007)$ \\
\hline \multirow[t]{2}{*}{$I N P L$} & 0.0036 & -0.0028 & 0.0076 \\
\hline & $(0.0193)$ & $(0.0172)$ & $(0.0215)$ \\
\hline \multirow[t]{2}{*}{ lodep } & -0.0000 & -0.0004 & -0.0004 \\
\hline & $(0.0003)$ & $(0.0002)$ & $(0.0003)$ \\
\hline \multirow[t]{2}{*}{ crisis } & 0.0010 & $0.0016^{*}$ & 0.0013 \\
\hline & $(0.0009)$ & $(0.0008)$ & $(0.0009)$ \\
\hline \multirow[t]{2}{*}{$E U 15$} & $-0.0023^{*}$ & $-0.0020^{*}$ & $-0.0028^{* *}$ \\
\hline & $(0.0014)$ & $(0.0011)$ & $(0.0014)$ \\
\hline \multirow[t]{2}{*}{ listed } & 0.0001 & -0.0004 & 0.0002 \\
\hline & $(0.0010)$ & $(0.0008)$ & $(0.0010)$ \\
\hline \multirow[t]{2}{*}{ constant } & $0.0179^{* * *}$ & $0.0226^{* * *}$ & $0.0094^{*}$ \\
\hline & $(0.0067)$ & $(0.0086)$ & $(0.0054)$ \\
\hline$N$ & 3101 & 3113 & 3145 \\
\hline AR(1) test (p-value) & 0.000 & 0.000 & 0.000 \\
\hline AR(2) test ( $p$-value) & 0.984 & 0.817 & 0.944 \\
\hline Lags & $2-4$ & $2-4$ & $2-4$ \\
\hline IV count (groups) & $442(448)$ & $442(445)$ & $401(450)$ \\
\hline Hansen ( $p$-value) & 0.600 & 0.573 & 0.341 \\
\hline Year Effects & Insignificant & Insignificant & Insignificant \\
\hline
\end{tabular}

${ }^{*} p<0.10,{ }^{* *} p<0.05,{ }^{* * *} p<0.01$. Windmeijer (2005) robust standard errors reported. AR(1) and $A R(2)$ are tests for first and second order serial correlation, under the null hypothesis of no serial correlation. The 'lags' show the number of lags used in the GMM model for bank specific variables. Our results hold under different lag choices. The Hansen test of over-identification is under the null that all instruments are valid. 